\title{
REVIEW
}

\section{4-h Efficacy of Glaucoma Treatment Options}

\author{
Anastasios G. P. Konstas - Luciano Quaranta - Banu Bozkurt • \\ Andreas Katsanos · Julian Garcia-Feijoo - Luca Rossetti • \\ Tarek Shaarawy $\cdot$ Norbert Pfeiffer $\cdot$ Stefano Miglior
}

To view enhanced content go to www.advancesintherapy.com

Received: December 25, 2015 / Published online: February 24, 2016

(c) The Author(s) 2016. This article is published with open access at Springerlink.com

\section{ABSTRACT}

Current management of glaucoma entails the medical, laser, or surgical reduction of intraocular pressure (IOP) to a predetermined level of target IOP, which is commensurate with either stability or delayed progression of visual loss. In the published literature, the hypothesis

Electronic supplementary material The online version of this article (doi:10.1007/s12325-016-0302-0) contains supplementary material, which is available to authorized users.

A. G. P. Konstas ( $\square)$

1st University Department of Ophthalmology, Aristotle University of Thessaloniki, Thessaloniki, Greece

e-mail: konstas@med.auth.gr

A. G. P. Konstas

3rd University Department of Ophthalmology, Aristotle University of Thessaloniki, Thessaloniki, Greece

L. Quaranta

Glaucoma Unit, University of Brescia, Brescia, Italy

B. Bozkurt

Department of Ophthalmology, Selcuk University, Konya, Turkey

\section{A. Katsanos}

Department of Ophthalmology, University of Ioannina, Ioannina, Greece is often made that IOP control implies a single IOP measurement over time. Although the follow-up of glaucoma patients with single IOP measurements is quick and convenient, such measurements often do not adequately reflect the untreated IOP characteristics, or indeed the quality of treated IOP control during the 24-h cycle. Since glaucoma is a 24-h disease and the damaging effect of elevated IOP is continuous, it is logical that we should aim to understand the efficacy of all

J. Garcia-Feijoo

University of Madrid, Madrid, Spain

L. Rossetti

Eye Clinic, San Paolo Hospital, University of Milan, Milan, Italy

T. Shaarawy

Glaucoma Sector, University of Geneva, Geneva,

Switzerland

N. Pfeiffer

University of Mainz, Mainz, Germany

S. Miglior

Department of Ophthalmology, University Bicocca of Milan, Milan, Italy 
treatment options throughout the 24 -h period. This article first reviews the concept and value of diurnal and 24-h IOP monitoring. It then critically evaluates selected available evidence on the 24-h efficacy of medical, laser and surgical therapy options. During the past decade several controlled trials have significantly enhanced our understanding on the 24-h efficacy of all glaucoma therapy options. Nevertheless, more long-term evidence is needed to better evaluate the 24-h efficacy of glaucoma therapy and the precise impact of IOP characteristics on glaucomatous progression and visual prognosis.

Keywords: 24-h efficacy; 24-h intraocular pressure control; Circadian intraocular pressure characteristics; Diurnal intraocular pressure; Glaucoma therapy options; Intraocular pressure monitoring; Ophthalmology

\section{INTRODUCTION}

Recent randomized controlled trials show that reduction in intraocular pressure (IOP) results in reduction in the rate of visual loss in most glaucoma patients [1]. In many studies the assumption is made that IOP control implies a single, or occasionally, a few daytime IOP measurements over time. Although the follow-up of glaucoma patients with single IOP measurements is quick and convenient, such measurements often do not reflect IOP control during the 24-h cycle [2-4]. Since glaucoma is a 24-h disease and the damaging effect of elevated IOP is continuous [5], it is logical that we should aim to control the IOP throughout the 24 -h period. This article reviews the value and future promise of 24-h IOP monitoring and discusses recent 24-h efficacy evidence on available glaucoma treatment options. The review is based on previously conducted studies, and does not involve any new studies of human or animal subjects performed by any of the authors.

A single IOP measurement gives data for only 1 min of the day and may not reflect the dynamic equilibrium during the other $1439 \mathrm{~min}$ of that day, or the IOP level between appointments. Even three or four measurements may not reflect glaucoma status. Current routine clinical practice involves single IOP readings at each patient visit owing to time/cost considerations. Consequently, the quality of IOP data, which we rely upon to diagnose and treat glaucoma and to choose between therapeutic options (medical, laser, surgery) is often inadequate and can be misleading [2, 5-11]. Ideally, a 24-h time-IOP profile, both without and following treatment, will optimize management and help determine the future probability and rate of deterioration in vision. Such data will also enhance our understanding of the role of elevated IOP in glaucoma initiation and progression.

The concept of 24-h IOP assessment and control has aroused interest in recent literature [6-27] and its application may hold future promise. Twenty-four-hour blood pressure monitoring is widely employed to assist patient management. Similarly, 24-h IOP monitoring can enhance the quality of IOP data and guide glaucoma management. Firstly, evaluation of untreated 24-h IOP, prior to initiation of therapy, provides the true peak IOP and the 24-h IOP profile. Secondly, 24-h IOP monitoring elicits the IOP level at which damage probably occurred and allows an optimal target IOP to be set. Finally, the relationship between damage and IOP is elicited in the individual patient $[3-5,8,9]$. 
The key 24-h characteristics are: (a) the mean 24-h IOP, (b) the fluctuation of 24-h IOP, and (c) the peak 24-h IOP. As yet the value of 24-h IOP testing in the long-term prognosis of glaucoma remains unproven. However, those with the worst untreated 24-h characteristics tend to show greater deterioration. This was demonstrated in a 24-h IOP study [7], which found a strong linear correlation between untreated peak IOP in exfoliation glaucoma (XFG; $r=0.71$ ) and primary open-angle glaucoma (POAG; $r=0.44$ ) and perimetric mean deviation at the time of diagnosis. A similar strong association was detected between mean 24-h IOP and untreated mean visual field loss in both XFG $(r=0.77)$ and POAG $(r=0.28)$ [7]. Hence, it is logical to assume that the worse 24-h IOP characteristics in XFG may account for the faster deterioration and worse prognosis.

For each patient with glaucoma, diurnal or 24-h IOP data will enhance our understanding of the role of elevated IOP in glaucoma initiation and progression. Although in this context it would appear ideal to obtain information on the 24-h control of all our glaucoma patients this is not a realistic strategy for most patients in most health systems. In contrast, reliable guidance on the 24-h efficacy of all available treatment options can be obtained by carrying out well-designed, randomized controlled trials, which, when published, can influence everyday practice. For example, a complete 24-h assessment of all monotherapy options will allow better separation between them and guide our day-to-day clinical management. Then, controlled 24-h IOP studies can supply convincing evidence for the superiority of a specific combined therapy regimen thus optimizing stepwise therapy. This is supported by previously published evidence comparing various medical therapy regimens where the true efficacy profile would not have been detected if it had not been for a complete 24-h IOP study. As evidenced by such studies, 24-h efficacy can differ meaningfully from daytime efficacy [10, 12-14, 21]. In the future, this research can also remove ambiguity as to the true efficacy of laser therapy and the overall success of a number of novel surgical options versus the gold standard surgical selection of trabeculectomy with mitomycin C.

Over the last decade 24-h IOP monitoring has allowed us to investigate the 24-h efficacy of many new antiglaucoma drugs $[7,10,12,13$, $15,18,19,21,23]$ and see the benefits of so doing. Our results have highlighted the unpredictability of single IOP measurements. Patients with apparent "good IOP control", often have unsatisfactory diurnal pressure control, such as large 24-h IOP fluctuation and undetected IOP spikes outside office hours. The practical significance is that we now routinely assess 24-h IOP control first before considering other factors such as inappropriate target IOP and compliance. To date, only Riva and coworkers [28] have investigated the long-term 24-h IOP control in travoprost-treated patients with POAG by performing repeated 24-h IOP measurements over a period of 5 years while on the same therapy. This study established that only mean untreated 24-h IOP and treated 24-h peak IOP during the 5-year follow-up period were risk factors for predicting treatment failure $(P<0.01)$. This trial [28] demonstrated a consistent pattern of long-term 24-h IOP lowering (27.8-28.6\%) which compares well with the previously reported short-term 24-h efficacy of travoprost monotherapy [6].

There is some evidence to suggest that surgery provides better 24 -h characteristics and yields a narrower 24-h fluctuation of IOP compared with laser and medical therapy [29, 30]. On the other hand, recent 24-h studies 
have indicated that a number of new antiglaucoma drugs (prostaglandin analogs, fixed combinations) significantly reduce 24 -h fluctuation of IOP $[6,12,15,18,23]$. It is not known how adjunctive therapy with these drugs compares to successful laser, or surgery. Further research is needed on the quality of 24-h IOP control obtained with the various therapeutic options. Little is currently known on the relationship between 24-h IOP characteristics with available treatment choices and the stage of glaucoma. Despite the fact that 24-h IOP characteristics probably vary in different types of glaucoma, our knowledge concerning how this relates to the choice of therapy is almost non-existent.

IOP fluctuates normally throughout the day by around 4-6 mmHg [2, 3, 5]. In ocular hypertensives, the diurnal fluctuation averages 6-8 $\mathrm{mmHg}$, with a high of $15 \mathrm{mmHg}$ possible $[1,2,4]$. In patients with glaucoma, the 24-h variation in IOP ranges between 6 and $15 \mathrm{mmHg}$ with an upper limit of about $40 \mathrm{mmHg}$ in extreme cases [2-4]. Typically, in most 24-h studies [2, 7, 10-21] on patients with glaucoma the untreated IOP is highest in the morning (between 6:00 am and 12:00 pm). In most of our patients the 10:00 am IOP measurement yields the highest mean IOP values [7, 12-19]. This accords with the aqueous synthesis pattern, which is significantly reduced during sleep at night [31]. However, there are many exceptions to this rule and the peak pressure may occur at any time throughout the day. The type of glaucoma can also influence the timing of peak IOP. In one study [3], $45 \%$ of patients with XFG and $22.5 \%$ of those with POAG exhibited the peak level of IOP outside office hours.

The timing and number of measurements can obviously influence the results: more measurements lead to more accurate 24-h IOP profile. A potential artifact with such measurements is the effect of hospitalization, or the impact of stay in a sleep laboratory. This may affect to a certain extent the pressure curve since it can disturb the activity pattern of the patient. However, by and large this influence cannot be avoided. Ideally, in the future continuous monitoring (e.g., with continuous home tonometry utilizing IOP sensors on a contact lens, or implants transmitting IOP data by telemetry, etc.) may become accurate, reliable and practical enough to find a place in day-to-day glaucoma management.

Optimal 24-h IOP control may provide the best long-term prognosis for chronic glaucoma. A major breakthrough in the future may be the development of an accurate, continuous IOP monitoring process, which will record and transmit IOP data every few minutes. To date there are limited data concerning long-term 24-h IOP control with currently available medications. The significance of specific 24-h IOP characteristics (mean 24-h IOP, range, maximum IOP) is not entirely understood and their impact on long-term prognosis requires further elucidation. It is important to document in the future the 24-h efficacy of adjunctive medical therapy.

\section{PATTERNS OF 24-H IOP IN HEALTH AND DISEASE}

\section{Pattern of IOP in Healthy Eyes}

Tonometry performed over a 24-h period may be subdivided into diurnal (daytime) and nocturnal (nighttime) pressure measurements. In most patients the rhythmic pattern of IOP oscillation exhibits peaks in the morning and troughs in the evening. In healthy normotensive eyes, the 24-h IOP fluctuation typically lies within a $5 \mathrm{mmHg}$ range [2, 32-36]. 
Drance [32] measured the IOP of 404 normal eyes 6 times between 6:00 am and 10:00 pm and found that $16 \%$ of these cases exhibited a fluctuation greater than $6 \mathrm{mmHg}$, while $42 \%$ of them exhibited their peak pressure at 06:00 am. Overall, the mean IOP fluctuation was $\quad 3.7 \pm 1.8 \mathrm{mmHg}$. Katavisto [36] documented the highest IOP values at $8.00 \mathrm{am}$ in $41 \%$ and at midnight in over $20 \%$ of 50 subjects with normal IOP. Their 24-h fluctuation of IOP averaged $3.17 \mathrm{mmHg}$. In the study by David et al. [33], the peak IOP of healthy eyes was established at the earliest morning measurement in $40.5 \%$, at mid-morning in $22.6 \%$, and at mid-day in $19 \%$ of investigated subjects. In a similar fashion, Newell and Krill [35] studied a normal cohort and documented the greatest frequency of peak IOP readings between 6:00 and 8:00 am.

One important parameter that can influence IOP fluctuation is body posture; the IOP measured in the sitting position is generally lower than that measured in the supine position at any given time [22, 37-40]. In a diurnal study performed by Chiquet and coworkers [37], supine IOP was significantly higher than sitting IOP, with a mean pressure difference of $2.2 \pm 2.9 \mathrm{mmHg}$ after $1 \mathrm{~min}, 0.9 \pm 3 \mathrm{mmHg}$ after $3 \mathrm{~min}$, and $1.9 \pm 3.8 \mathrm{mmHg}$ after $10 \mathrm{~min}$ $(P<0.001)$. Nevertheless, during a seven-day head-down tilt bed rest, eyes seemed to compensate for the IOP elevation after patients assumed the head-down position and eventually exhibited a slight and progressive decrease of IOP $(1.3 \mathrm{mmHg})$ compared to the baseline supine IOP [37]. The decrease in IOP reached a peak value at the end of the week of the head-down position. In a 24-h study conducted by Liu et al. [38], 33 volunteers were housed in a sleep laboratory for one day under a strictly controlled 16-h light and 8-h dark environment and their IOP was measured every $2 \mathrm{~h}$ using a pneumotonometer. In the first group of 12 volunteers, habitual measurements were performed with subjects seated during the light-wake period and resting in a supine position during the dark period [38]. Nocturnal IOP was reported to be higher than diurnal IOP in the habitual position, with the difference between peak to trough IOP as high as $8.2 \pm 1.4 \mathrm{mmHg}$. The increase in IOP at night was partly attributed by the authors to an increase in episcleral venous pressure and redistribution of body fluid in the supine position. In the second part of the study performed on 21 subjects, mean IOP was significantly higher in the dark period than in the light-wake period [38] even when all IOP measurements were made in the supine position, implicating factors other than episcleral venous pressure in the observed 24-h IOP pattern. This group of investigators had also showed higher mean nocturnal IOP measurements compared to diurnal IOP levels in habitual body position both in an aging healthy cohort and in a group of untreated open-angle glaucoma patients [21, 39].

\section{IOP Pattern in Primary Open-Angle and Normal Tension Glaucoma}

In diurnal IOP monitoring studies, approximately two-thirds of the patients with untreated normal tension glaucoma (NTG) or untreated POAG have been reported to display peak IOP in the morning [33, 34, 41-43]. In the diurnal study performed by David et al. [33], the highest IOP was found at the earliest morning measurement in $40 \%$ of cases, while $65 \%$ of peak IOP readings occurred before noon. The trough IOP measurement showed no specific predilection for any particular time of the day [33]. The mean fluctuation of IOP was $5.0 \mathrm{mmHg}$ in normal controls, $5.8 \mathrm{mmHg}$ in 
patients with glaucoma and $6.8 \mathrm{mmHg}$ in patients with ocular hypertension (OHT). In the study by Wilensky et al. [34], a group of 176 patients with POAG, 55 subjects with OHT and 18 normal controls performed home self-tonometry 5 times daily for 4 to 8 consecutive days. All three groups had well-defined diurnal IOP fluctuations with predominance of curves exhibiting morning or mid-day peaks. In the study by Sacca et al. [41], IOP measurements were performed on 33 healthy volunteers, 95 patients with POAG and 50 with NTG every $2 \mathrm{~h}$ from 8:00 am to $8: 00 \mathrm{pm}$. The highest pressure readings were seen in the morning in all three groups, while the lowest values were recorded in the early afternoon period. The daily IOP fluctuations were directly proportional to IOP levels. The fluctuations were higher in the POAG group $(-7 \%$ to $+9.6 \%)$ than the control group $(-3.4 \%$ to $+6.9 \%)$ and the NTG group $(-4.7 \%$ to $+6.4 \%)$. Collaer and coworkers [44] investigated 53 patients with NTG, 12 glaucoma suspects, and 28 patients with POAG and were broadly in agreement with the previous investigations. The characteristics of their diurnal IOP curve performed between 7:00 am and 5:00 pm were similar in all 3 patient groups: higher IOP in the early morning, lower in the early afternoon, and a tendency for pressure to rise again at the end of the afternoon [44]. In this study mean diurnal IOP fluctuation was $5 \pm 2 \mathrm{mmHg}$. In a retrospective chart review study [42], diurnal IOP measurements of 68 untreated glaucoma suspects and 95 patients with NTG were performed at 10:00 am, 1:00 pm, 4:00 pm, 7:00 pm, 10:00 pm, and 7:00 am. Again in the glaucoma suspects, the peak IOP was noted in the morning: at 7:00 am in the right eye and at 10:00 am in the left eye. The trough IOP was observed at 10:00 pm for both eyes. For both eyes of patients with NTG, the peak IOP occurred at 7:00 am and the trough IOP was measured at 10:00 pm. In another study [43], diurnal IOP fluctuations between 7:00 am and 10:00 pm were found to be significantly higher in primary chronic angle-closure glaucoma (PCACG; $\quad 7.7 \pm 3.0 \mathrm{mmHg}$ ) and POAG $(8.3 \pm 2.6 \mathrm{mmHg})$ groups compared to the normal controls $(4.8 \pm 2.5 \mathrm{mmHg})$. Afternoon peaks were more common after iridotomy in eyes with PCACG, whereas morning peaks were more frequent in the POAG eyes. In POAG, the IOP fluctuations between 8:00 am and 6:00 pm on different days were found to be broadly similar $\quad(5.0 \pm 2.6 \quad$ vs. $\quad 4.0 \pm 1.2 \mathrm{mmHg}$; $P=0.08)$.

It is well established that 24-h IOP monitoring may reveal higher peaks and wider fluctuations than those recorded during office hours $[9,11,20,21,45]$. Nevertheless, conflicting results have been published as to the time of peak pressure, the pattern of the curve, and the extent IOP fluctuation. In some studies, the timing of peak IOP during pressure monitoring exhibited no apparent pattern [9, 20]. In a retrospective chart review of 18 patients with NTG and 11 with POAG using their prescribed topical antiglaucoma treatment, Hughes et al. [9] reported that the mean peak IOP during 24-h monitoring was $4.9 \mathrm{mmHg}$ higher than the mean peak office IOP determined in the clinic during previous visits, despite the fact that the mean office IOP was similar to the mean 24 -h value. The mean 24-h IOP fluctuation documented was $9.4 \pm 4.2 \mathrm{mmHg}$. Eleven patients had morning peak (6:00-11:30 am), 8 patients exhibited an afternoon peak (12:00-5:30 pm) and 10 patients showed evening peak pressures (6:00 pm-12:00 am). Fifteen patients (51.7\%) had peak IOP values outside the typical office hours, and in $14 \%$ of them the peak circadian 
IOP was at least $12 \mathrm{mmHg}$ higher than the peak documented during office hours. Importantly, circadian IOP measurements led to clinical management modifications in almost $80 \%$ of patients as a consequence of detecting either large 24-h IOP fluctuation and/or high IOP spikes that had not been previously detected in an office setting. The authors also argued that the use of Tono-Pen ${ }^{\circledR}$ (Reichert, Inc.) in 24-h IOP monitoring may in fact have underestimated IOP peaks and fluctuation, as previous evidence suggests that Tono-Pen may produce lower values than the gold standard (Goldmann tonometry) [21]. In a large study [20] where 3.025 day-and-night IOP profiles were measured in 1072 eyes of 547 Caucasian patients with glaucoma, or glaucoma suspects with Goldmann tonometry, the peak IOP value was detected at 7:00 am, noon, 5:00 pm, 9:00 pm, and midnight, respectively, in $20.4 \%$, $17.8 \%, 21.3 \% 13.9 \%$, and $26.7 \%$ of the cases investigated.

In a 24-h monitoring study performed by Tajunisah et al. [11], on 202 eyes of open-angle glaucoma suspects, most of the subjects had peak readings in the mid-morning (10:00-11:00 am) and trough readings after midnight (2:00-3.00 am), with a mean fluctuation of $6 \mathrm{mmHg}$. Dinn et al. [45], in a retrospective chart review, investigated the concordance of 24-h IOP in fellow eyes of 37 untreated and 56 treated patients with POAG who were using the same topical medication in both eyes. The circadian IOP variation was largely concordant in the fellow eyes of both groups. The mean difference in IOP change between fellow eyes over the given time intervals was found to range from 1.6 to $2.0 \mathrm{mmHg}$. In the untreated group, peak IOP occurred at 7:00 am and trough IOP occurred at 09:00 pm, and in the treated group, peak IOP occurred at 10:00 am without a trend of decreasing IOP in the course of the day. Nakakura et al. [46] examined 24-h IOP in 42 patients with POAG treated with combinations of latanoprost, beta-blockers, and carbonic anhydrase inhibitors in the sitting position with a Goldmann tonometer at 3-h intervals. In this study mean office IOP was similar to mean 24-h IOP. However, there was no correlation between office IOP and 24-h IOP fluctuation, or between office IOP fluctuation and 24 -h IOP fluctuation. Only 6 eyes (8.5\%) showed 24-h IOP fluctuation lower than $3 \mathrm{mmHg}$. Peak 24-h IOP occurred during office hours in only $34 \%$ of eyes, whereas trough 24 -h IOP occurred during office hours in $72 \%$ of eyes. In the study of Tanaka et al. [47], IOP measurements at 14 time points $(12: 00 \mathrm{pm}$, 3:00 pm, 6:00 pm, 9:00 pm, 12:00 am, 6:00 am, 9:00 am, 12:00 pm, 3:00 pm, 6:00 pm, 9:00 pm, 12:00 $\mathrm{am}, \quad 6: 00 \mathrm{am}$, and 9:00 am) were performed over a period of $48 \mathrm{~h}$ in 18 untreated POAG eyes and 43 treated POAG eyes. A nocturnal acrophase pattern with a remarkable pressure increase at midnight was observed in treated eyes, although the non-treated patients group did not show such an apparent IOP circadian pattern. Among the different medication groups, a nocturnal acrophase circadian pattern was observed in patients being treated by combinations of prostaglandins and beta-blockers or prostaglandin analogs, beta-blockers and carbonic anhydrase inhibitors. However, this was not apparent in patient groups with single antiglaucoma medications or the concomitant use of prostaglandins and carbonic anhydrase inhibitors.

Liu et al. [22] reported that 24-h IOP was higher, the diurnal-to-nocturnal change of habitual IOP was less noticeable, and the posture-independent IOP pattern around normal awakening time was different in eyes 
with early glaucomatous changes compared to healthy eyes. In a multicenter, prospective study carried out by Quaranta et al. [48], untreated patients with OHT or POAG underwent sitting IOP measurements over a 24-h period by Goldmann tonometry and supine nighttime IOP measurements by Perkins tonometer. The mean sitting 24-h IOP was significantly lower than the supine IOP $(22.5 \pm 3.7$ vs. $23.5 \pm 4.3 \mathrm{mmHg} ; \quad P<0.001)$. The mean sitting IOP across the three daytime points measured was statistically higher than the sitting IOP across the three nighttime points measured $\quad(23.3 \pm 3.4$ vs. $21.5 \pm 4.0 \mathrm{mmHg}$; $P<0.001)$, but was not statistically different from the mean nighttime supine IOP evaluated with Perkins tonometry $(22.8 \pm 4.4 \mathrm{mmHg}$; $P=0.07)$.

Although valuable, it should be acknowledged that 24-h IOP monitoring might be impractical or even impossible in most glaucoma patients. Therefore, the identification of surrogate measures that may accurately reflect nocturnal IOP characteristics is clinically desirable. To address this issue, Mosaed et al. [49] reviewed 24-h IOP data collected from 33 younger healthy subjects (aged 18-25 years), 35 older healthy subjects (aged 40-74 years), and 35 untreated older glaucoma patients (aged 40-79 years) housed in a sleep laboratory and measured in habitual body position. In all three groups, peak IOP for each individual occurred for the most part in the supine position during the nocturnal period. In older glaucoma patients, significant correlations were found between average office-hour sitting IOP and peak nocturnal IOP $(r=0.601 ; \quad P<0.001)$, and between average office-hour supine IOP and peak nocturnal IOP $(r=0.713 ; P=0.001)$. In glaucoma patients, the majority $(67 \%)$ of the peak 24 -h IOP values in habitual body positions occurred at night.
Using linear regression, the investigators produced two formulas: peak nocturnal $\mathrm{IOP}=12.04+0.616 \times$ average office-hour sitting IOP $\left(r^{2}=0.361\right)$, and peak nocturnal $\mathrm{IOP}=5.98+0.771 \times$ average office-hour supine IOP $\left(r^{2}=0.508\right)$. The authors suggest that these formulas may help clinicians predict peak nocturnal IOP values, based on office-hour sitting or supine readings in a significant proportion of older patients with glaucoma.

\section{Diurnal/24-h IOP Control with Medical Therapy in POAG and OHT}

In a meta-analysis of previously randomized, prospective, crossover or parallel, single or double-masked trials evaluating the effects of timolol on diurnal and nighttime IOP and blood pressure in subjects with POAG and OHT, a reduction from baseline was observed for timolol at each time point and for the 24-h curve $(P \leq 0.009)$ [50]. Both timolol $0.5 \%$ and timolol hydrogel $0.1 \%$ significantly decreased diurnal, nocturnal, and individual time point IOP in 24-h period in patients with POAG [51]. Both timolol formulations demonstrated minimal effects on blood pressure and calculated diastolic ocular perfusion pressure.

In a 24-h IOP study performed by Feldman et al. [52], patients with open-angle glaucoma and OHT insufficiently controlled (IOP $\geq 22 \mathrm{mmHg}$ ) on monotherapy were randomized to either dorzolamide/timolol fixed combination (DTFC; $n=117$ ) or timolol $(n=115)$. Both of the treatments provided significant IOP reduction over the entire 24-h measurement period. DTFC exhibited greater IOP-lowering than timolol during the daytime, but there was no significant difference at night. In another study on 1159 subjects with POAG and $\mathrm{OHT}$, the percentage of patients with mean diurnal IOP $<18 \mathrm{mmHg}$ and daytime IOP 
fluctuation less than $2 \mathrm{mmHg}$ was statistically significantly higher in the brimonidine/timolol fixed combination group than in the brimonidine tartrate $0.2 \%$, or timolol maleate 0.5\% groups $(P=0.017) \quad$ [53]. The brimonidine/timolol fixed combination and the concomitant administration of brimonidine and timolol provided significant 24-h IOP reduction from untreated baseline, and were statistically equal when compared directly, at each time point and for the 24-h pressure curve in patients with POAG and OHT [54].

Prostaglandin analogs are more potent and decrease IOP fluctuation more than other antiglaucoma medications. In a meta-analysis of randomized clinical trials evaluating the IOP-lowering effects of commonly used glaucoma drugs in subjects with POAG and OHT, relative IOP reductions from baseline were documented to be: $-23 \%$ at peak and $-20 \%$ at trough for betaxolol $0.5 \% ;-27 \%$ at peak and $-26 \%$ at trough for timolol $0.5 \% ;-22 \%$ at peak and $-17 \%$ at trough for dorzolamide $2.0 \%$; $-17 \%$ at peak and $-17 \%$ at trough for brinzolamide $1.0 \% ;-25 \%$ at peak and $-18 \%$ at trough for brimonidine $0.2 \% ;-31 \%$ at peak and $-28 \%$ at trough for latanoprost $0.005 \%$; $-31 \%$ at peak and $-29 \%$ at trough for travoprost $0.004 \% ;-33 \%$ at peak and $-28 \%$ at trough for bimatoprost $0.03 \%$; and finally $-5 \%$ at peak $-5 \%$ at trough for the placebo [55]. In the crossover study by Orzalesi et al. [10], 10 patients with POAG and 10 patients with OHT were treated with timolol, latanoprost, and dorzolamide for 1 month in a randomized sequence. All patients underwent four 24-h IOP curves: at baseline and after each 1-month treatment period. IOP measurements were performed at 3:00 am, 6:00 am, 9:00 am, noon, 3:00 pm, 6:00 pm, 9:00 pm and midnight using Tono-Pen with the patient supine and sitting, and a Goldmann applanation tonometer with the patient sitting at the slit lamp. In this group, the highest IOP values were measured at 9:00 am and the lowest values at midnight and 3:00 am both in the sitting and supine positions [10]. Latanoprost was more effective than dorzolamide and timolol and seemed to lead to a fairly uniform circadian reduction in IOP. Timolol was more effective than dorzolamide at $3: 00 \mathrm{pm} \quad(P=0.05)$, whereas dorzolamide performed better than timolol at midnight and 3:00 am $(P=0.05)$. In another 24 -h study, Liu et al. [56] compared once-daily timolol and latanoprost in patients with OHT, or early glaucomatous changes employing a pneumotonometer. Sitting and supine measurements were taken during the 16-h diurnal period whereas only supine measurements were taken during the 8-h nocturnal period. In the diurnal period, the mean IOP in the timolol and latanoprost treatment periods were significantly less than the mean untreated IOP in both the sitting and the supine positions. In contrast, during the nocturnal period mean supine IOP on timolol therapy was significantly higher than mean supine IOP on latanoprost therapy.

The evening administration of latanoprost, or the combination of latanoprost and timolol resulted in lower daytime IOP than the morning dosing of these drugs in patients with POAG $[12,15]$. In a more recent $24-\mathrm{h}$ study, Konstas et al. [57] compared latanoprost and preservative-free tafluprost both dosed in the evening in 38 patients with either POAG or OHT. This study employed Goldmann technology (Goldmann tonometer for sitting IOP at 10:00 am, 2:00 pm, 6:00 pm, and 10:00 pm, and Perkins tonometry for supine readings at 2:00 am and 6:00 am). Preservative-free tafluprost demonstrated similar 24-h efficacy to latanoprost (17.8 vs. 
$17.7 \mathrm{mmHg} ; \quad P=0.417) . \quad$ Interestingly, latanoprost demonstrated significantly better 24-h trough IOP (15.9 vs. $16.3 \mathrm{mmHg}$; $P=0.041) \quad$ whereas tafluprost provided significantly lower 24-h IOP fluctuation (3.2 vs. $3.8 \mathrm{mmHg} ;=0.008$ ) [57].

Latanoprost-timolol fixed combination decreased IOP more than latanoprost or timolol monotherapy at each time point and for the 24-h curve, and demonstrated a narrower range of IOP fluctuation in patients with POAG and OHT [58, 59]. Quaranta et al. [60] showed that both DTFC and latanoprost $0.005 \%$ significantly reduced 24-h IOP in patients with POAG $(P<0.0001)$, but DTFC achieved lower mean 24 -h IOP $(15.4 \pm 1.9$ vs. $16.7 \pm 1.7 \mathrm{mmHg} ; \quad P=0.004)$. In agreement with this study, Konstas et al. [61] investigated 39 patients with POAG and 14 with OHT after 2 and 6 months of therapy and reported almost similar 24-h efficacy between the DTFC and latanoprost. In a double-blind, prospective crossover clinical comparison trial on 36 patients with POAG with insufficiently controlled IOP despite treatment with latanoprost monotherapy, the addition of dorzolamide or timolol led to a significant lowering of 24-h IOP $(P<0.05)$ [62]. However, the IOP reduction was greater with the latanoprost and dorzolamide regimen, especially at nighttime [62]. In a similar study, dorzolamide or brinzolamide combined with latanoprost elicited a significant 24-h IOP reduction [63]. In the study by Lupinacci et al. [64], diurnal IOP control between 8:00 am and 8:00 pm was similar in the twice daily versus three-times daily dosing of dorzolamide as adjunctive therapy to latanoprost in patients with POAG, although mean IOP reduction was significantly lower at $6: 00 \mathrm{pm}$ on the three-times daily regimen of dorzolamide $(4.7 \pm 3.3$ vs. $\quad 2.3 \pm 2.7 \mathrm{mmHg} ; \quad P=0.038)$.
Further, brimonidine purite and dorzolamide added to latanoprost have both been found to have similar 24-h efficacy and safety in subjects with POAG or OHT [65].

Katsanos et al. [66] investigated the mean diurnal fluctuation of patients with OHT, POAG, or XFG. Based upon 4 measurements taken between 8:00 am and 8:00 pm diurnal fluctuation decreased from $6.8 \pm 3.2 \mathrm{mmHg}$ at baseline to $4.0 \pm 3.1$ and $2.9 \pm 1.4 \mathrm{mmHg}$ on bimatoprost and bimatoprost/timolol fixed combination, respectively $(P<0.05$ for both treatments versus baseline). In another study by Rossetti et al. [67], bimatoprost was found as effective as latanoprost/timolol fixed combination (LTFC) in maintaining 24-h IOP in patients with glaucoma or OHT switched from the unfixed combination of latanoprost and timolol.

In a 24-h study by Seibold and Kahook [68], IOP measurements were taken using a pneumotonometer every $2 \mathrm{~h}$ in the sitting position during the 16 -h diurnal period and in the supine position during the 8-h nocturnal period in 40 subjects with open-angle glaucoma and OHT. Travoprost with SofZia ${ }^{\mathrm{TM}}$ (Alcon Laboratories) lowered IOP throughout the diurnal and nocturnal periods, and increased ocular perfusion pressure in the diurnal, but not the nocturnal period. The hypotensive effect endured for at least $84 \mathrm{~h}$ after the last dose. Riva et al. [28] showed that travoprost uniformly reduced mean 24-h IOP from $23.4 \pm 1.7 \mathrm{mmHg}$ at baseline to $16.8 \pm 2.4 \mathrm{mmHg} \quad(28.4 \%)$, $16.8 \pm 2.5 \mathrm{mmHg} \quad(28.1 \%), \quad 16.8 \pm 2.4 \mathrm{mmHg}$ (28.5\%), $\quad 16.7 \pm 2.5 \mathrm{mmHg} \quad(28.6 \%), \quad$ and $16.9 \pm 2.4 \mathrm{mmHg}(27.8 \%)$, respectively, at the end of the first, second, third, fourth, and fifth year in 36 patients with POAG. In patients with open-angle glaucoma insufficiently controlled on travoprost monotherapy, the addition of brinzolamide/timolol or brimonidine/timolol 
fixed combinations provided clinically meaningful and statistically significant incremental 24-h IOP lowering [69]. However, brinzolamide/timolol fixed combination obtained significantly better 24-h IOP control owing to the greater efficacy between $6: 00 \mathrm{pm}$ and 2:00 am [69]. In another meta-analysis evaluating the IOP-lowering effects of commonly used fixed combination drugs containing timolol, the relative reductions for mean diurnal IOP were found to be $34.9 \%$ for travoprost/timolol, $34.3 \%$ for bimatoprost/ timolol, 33.9\% for latanoprost/timolol, 32.7\% for brinzolamide/timolol, $29.9 \%$ for dorzolamide/timolol, and $28.1 \%$ for the brimonidine/timolol fixed combinations [70].

\section{IOP Pattern in Exfoliation Syndrome and XFG}

It is worth noting that 24-h IOP characteristics are generally worse in secondary open-angle glaucoma (e.g., pigmentary glaucoma and XFG). Most likely this is a consequence of intermittent dispersion of pigment and exfoliation material onto the trabecular meshwork. Patients with XFG typically exhibit greater 24-h fluctuation, peak and trough IOP than patients with POAG [3, 71]. Konstas et al. [3] have reported a 24-h IOP fluctuation higher than $15 \mathrm{mmHg}$ in $35 \%$ of patients with XFG, but only in $7.5 \%$ of patients with POAG. The authors documented peak IOP to be outside office hours (10:00 pm-6:00 am) in almost 45\% of patients with XFG and $22.5 \%$ of patients with POAG [3]. A rhythmic pattern of IOP fluctuation was seen, with the 10:00 am IOP measurement yielding the peak IOP value in both XFG and POAG cohorts, whereas the lowest mean value for both glaucoma groups was obtained at 2:00 am [3]. Further, in the diurnal study by Gumus et al. [72], peak IOP was also found to be highest in the morning both in subjects with exfoliation syndrome (XFS) and in the control group. All in all IOP showed a gradual decrease from 8:00 am to 6:00 pm in the control group, whereas a second peak at 3:00 pm was observed only in the XFS group. Eyes with XFS and high diurnal IOP fluctuation displayed lower retinal nerve fiber layer thickness measurements with scanning laser polarimetry [72]. Huchzermeyer et al. [73] compared the 24-h IOP profile of 39 eyes with XFS and 39 matched control eyes and found that patients with XFS had significantly higher levels of IOP fluctuation $(2.76 \pm 1.2 \mathrm{mmHg})$ compared with controls $(2.2 \pm 1.1 \mathrm{mmHg}$; $P<0.001)$.

\section{Diurnal/24-h IOP Control with Medical Therapy in XFG}

Timolol $0.5 \%$ solution twice daily and timolol maleate $0.5 \%$ gel-forming solution once daily were both shown to control 24-h IOP in patients with POAG and XFG in a similar fashion. However, a trend to lower pressures was observed in both patients with XFG and POAG with timolol solution [74]. In a 24-h study by Konstas et al. [75], 23 patients with POAG and 11 patients with XFG were randomized to topical travoprost/timolol fixed combination (TTFC) administered either in the morning or evening for a period of 8 weeks. The IOP was measured at 10:00 am, 2:00 pm, 6:00 pm, 10:00 pm, 2:00 am, and 6:00 am. Patients were then crossed over to the alternative dosing regimen for another 8 weeks and 24-h IOP measurements were repeated. In untreated patients, the mean IOP was highest at 6:00 am (28.8 $\pm 4.3 \mathrm{mmHg})$ and 10:00 am $(29.5 \pm 3.2 \mathrm{mmHg})$, and lowest at $10: 00 \mathrm{pm}$ $(26.4 \pm 4.5 \mathrm{mmHg}) \quad$ and $2: 00 \mathrm{am} \quad(25.3 \pm$ $3.8 \mathrm{mmHg}$ ). Both dosing regimens reduced IOP 
from baseline at each time-point and for the mean 24-h curve $(P<0.01)$. However, evening dosing provided a significantly lower 24 -h mean IOP $(18.4 \pm 3.3 \mathrm{mmHg})$ and more narrow IOP fluctuation $(3.8 \pm 1.6 \mathrm{mmHg})$ than the morning dosing $\quad(19.2 \pm 3.5$ and $5.1 \pm 1.6 \mathrm{mmHg}$, respectively; $P<0.001$ ). In a 24 -h study, Konstas et al. [76] compared the 24-h IOP control provided by the morning and evening administration of the bimatoprost/timolol fixed combination and the evening administration of bimatoprost in one eye of 60 patients with XFG. Bimatoprost monotherapy reduced mean 24-h IOP by $27.8 \%$. The evening administration of the fixed combination provided superior 24-h IOP control than the morning administration (35.3\% vs. $33.8 \%)$. In their meta-analysis of 24-h IOP fluctuation studies and the efficacy of glaucoma medicines, Stewart et al. [77] established that bimatoprost demonstrates the greatest reduction in 24-h fluctuation (3.4 mmHg) among various glaucoma treatments $(P=0.03)$ and reported that patients with XFG generally demonstrate a greater decrease in fluctuations than patients with POAG $(P=0.003)$.

\section{Diurnal/24-h Fluctuation and Glaucoma Progression}

The potential detrimental role of large IOP fluctuations in the development or progression of glaucoma has received increasing attention $[8,25,78-83]$. Based on the concept that large diurnal IOP fluctuation and high peak IOP may be harmful to the glaucomatous optic nerve, many clinicians now feel that optimal glaucoma therapy should aim to minimize the circadian IOP fluctuation and to eliminate as much as possible the pressure spikes [9]. However, it is uncertain as yet which 24-h IOP parameter (peak, mean, or fluctuation) is more important in disease progression. Barkana et al. [84] performed a chart review of 32 patients with open-angle glaucoma whose office IOP readings did not seem to explain the severity or glaucomatous progression. All patients were medically treated or had undergone laser trabeculoplasty and/or trabeculectomy. Pressure monitoring was carried out employing Goldmann tonometry in the sitting position from 7:00 am until midnight and Perkins tonometry in the supine position at 6:00 am. Peak IOP was detected outside of office hours in at least one eye in nearly $70 \%$ of their patients. Peak 24-h IOP was higher than that recorded in the office in $62 \%$ of cases and mean IOP fluctuation during 24-h monitoring $(6.9 \pm 2.9 \mathrm{mmHg})$ was significantly greater than that measured during office hours $(3.8 \pm 2.3 \mathrm{mmHg} ; \quad P<0.001)$. The results of this 24-h IOP monitoring study led to immediate treatment change in at least one eye of almost $60 \%$ of study patients. In the study of Asrani et al. [8], the diurnal IOP range of 5 measurements obtained in a day using home tonometry and the IOP range over 5 days were found to be significant risk factors for progression in 105 eyes of 64 patients with open-angle glaucoma. However, this study has raised some methodological issues and no study since has replicated this research approach. In another study by Bergea et al. [25], diurnal IOP measurements and automated visual field tests were performed in 76 patients for 2 years, the majority of whom had XFG and both mean IOP and IOP variation (range and peak) were found to be significant predictors of glaucoma progression.

In the study by Wilensky et al. [78], more than half of the patients with glaucoma investigated had one or more IOP readings above $22 \mathrm{mmHg}$ with self-tonometry applied 5 times a day between awakening and bedtime for 
3 to 6 days, although they had an IOP of $22 \mathrm{mmHg}$ or less at 3 consecutive visits before recruitment into the study. Moreover, the peak IOP was measured either before 8:00 am or after 5:00 pm in nearly half of these cases, which means they were unlikely to have been detected in a routine office visit. More elevated IOP readings were recorded in patients with suspected or documented progression of glaucomatous damage than in patients thought to be stable or in normal subjects. In the diurnal study conducted by Thomas et al. [79], mean IOP fluctuation was found to be $8.6 \mathrm{mmHg}$ in subjects with OHT that later converted to POAG, as compared to only $5.4 \mathrm{mmHg}$ in the group that did not convert to glaucoma. After 5 years, 4 of 23 patients with OHT had converted to POAG. Thus, the 5-year incidence of POAG amongst subjects with OHT was $17.4 \%$ (95\% CI $1.95-32.75)$, or $3.5 \%$ per year. The relative risk of conversion amongst patients with OHT was 19.1 (95\% CI 2.2-163.4). Bilateral OHT, higher peak IOP, and large diurnal variation were shown to be the risk factors for conversion. In the diurnal study of Gonzalez et al. [80] which included 149 subjects with OHT, $82 \%$ of cases with a flat diurnal curve preserved their normal visual field, whereas $64 \%$ of cases with an IOP fluctuation greater than $5 \mathrm{mmHg}$ developed a glaucomatous visual field defect within a follow-up period of 4 years $(P<0.05)$.

In contrast, a study performed by Jonas and coworkers [81] did not find a relationship between diurnal IOP fluctuation and glaucomatous progression. This study relied on sitting Goldmann measurements performed at 7:00 am, noon, 5:00 pm, 9:00 pm, and midnight obtained from 458 Caucasian patients with chronic open-angle glaucoma or OHT [81]. The authors concluded that, while mean IOP exerts a significant influence upon the rate of glaucomatous progression, IOP fluctuation does not demonstrate such an association.

\section{4-H EFFICACY OF MONOTHERAPIES}

Clinical management of a patient with glaucoma is primarily based on establishing an individual target IOP that can vary depending upon parameters such as age, visual field damage, rate of progression, baseline IOP, and overall risk profile. Treatment options must be selected so that target IOP is attained considering 24-h drug efficacy. The following section presents clinical efficacy data of antiglaucoma drug classes as highlighted by key published studies.

\section{Prostaglandin Analogs}

Prostaglandins are currently the most potent topical antiglaucoma medications, achieving a mean 24-h IOP reduction of $24-29 \%[6,85]$. Their efficacy appears to be fairly uniform throughout the circadian cycle [6], although 24-h studies generally have demonstrated that the peak efficacy of all prostaglandins occurs 8-12 $\mathrm{h}$ after administration [10, 12, 15, 17, 76]. Published evidence indicates that prostaglandin efficacy is greater during the morning/daytime with evening dosing $[12,27,77]$. All prostaglandins are thought to exert their ocular hypotensive effect by increasing the uveoscleral (and to a lesser extent the trabecular) outflow of aqueous [86]. Their superior 24-h efficacy profile and their convenient dosing (once daily, mostly in the evening) have made prostaglandins a popular first-choice glaucoma therapy.

Latanoprost, the first member of this class became commercially available in 1996. It is a 
prostaglandin F2 $\alpha$ isopropyl ester pro-drug, which is rapidly hydrolyzed by esterases in the cornea to the biologically active latanoprost acid [87]. Its efficacy has been extensively compared with other commonly used glaucoma medications. Orzalesi and coworkers [10] evaluated the 24-h IOP reduction achieved with latanoprost in POAG and OHT. They established that latanoprost was more efficacious in lowering IOP than the prototype beta-blocker timolol at 3:00 am, 6:00 am, 9:00 am, 12:00 am, 9:00 pm, and at midnight. It was also more effective than the topical carbonic anhydrase inhibitor dorzolamide at 9:00 am, noon, 3:00 pm, and 6:00 pm. Quaranta et al. [85] reported similar results: latanoprost was more efficacious than timolol from 10:00 pm to $6: 00 \mathrm{am}$. No significant differences in IOP were found for the period between 8:00 am and 8:00 pm between timolol and latanoprost, while dorzolamide was as effective as latanoprost during the night from 10:00 pm to 6:00 am.

The peak efficacy of latanoprost remains a matter of debate and may differ from patient to patient, but is generally thought to occur approximately $8-12 \mathrm{~h}$ after administration [12, 88]. In a 6-month randomized, double-masked, multicenter study with three parallel groups (latanoprost dosed either in the morning or evening and timolol), Alm and Stjernschantz [89] showed that timolol reduced the mean diurnal IOP from 24.6 to $17.9 \mathrm{mmHg}$ (27\%), morning-dosed latanoprost from 25.5 to $17.7 \mathrm{mmHg} \quad(31 \%)$ and evening-dosed latanoprost from 24.8 to $16.2 \mathrm{mmHg}$ (35\%). The efficacy of evening-dosed latanoprost was statistically superior to morning-dosed latanoprost and to timolol $(P<0.001)$. The 24-h efficacy of morning versus evening administration of latanoprost was compared in a crossover study by Konstas et al. [12]. These authors reported that both regimens were efficacious over the $24 \mathrm{~h}$, but evening administration provided a statistically lower IOP at 10:00 am, while morning administration provided a statistically lower pressure at 10:00 pm. At the critical 6:00 am time-point, when IOP is often high in patients with glaucoma, both dosing regimens were equally efficacious. On the basis of this pattern, clinicians may select the optimal time of administration depending on each patient's circadian IOP profile. However, since evening dosing induced lower 24-h IOP fluctuation compared with morning administration $(4.4 \pm 1.8 \quad$ vs. $\quad 5.7 \pm 2.4 \mathrm{mmHg}) \quad$ evening administration may be preferable in most patients.

In an 8-week treatment, prospective, crossover, double-masked comparison, Konstas et al. [90] evaluated the quality of 24-h IOP control between morning- and evening-dosed travoprost in patients with POAG. The untreated mean circadian IOP was $23.6 \pm 2.0 \mathrm{mmHg}$. There were no differences for mean 24-h IOP between the morning $(17.5 \pm 1.9 \mathrm{mmHg}) \quad$ and evening $(17.3 \pm 1.9 \mathrm{mmHg}) \quad$ dosing $\quad(P=0.7) . \quad$ At 10:00 am, the evening dosing provided a statistically lower IOP $(17.2 \pm 2.1 \mathrm{mmHg})$ than the morning dosing $(19.1 \pm 2.5 \mathrm{mmHg}$; $P=0.02$ ). Evening dosing demonstrated a statistically lower 24-h fluctuation of IOP $(3.2 \pm 1.0 \mathrm{mmHg})$ than morning dosing $(4.0 \pm 1.5 \mathrm{mmHg} ; \quad P=0.01)$. This study suggests that both morning and evening dosing of travoprost provide effective 24-h IOP reduction. However, the evening dosing of travoprost demonstrates slightly greater daytime efficacy, with a narrower range of 24-h pressure.

The relative 24-h efficacy of each prostaglandin analog has been the subject of 
intense investigation. The first head-to-head, parallel arms, daytime comparison between latanoprost, bimatoprost and travoprost was conducted by Parrish et al. [91]. In this investigation, neither the magnitude nor the pattern of daytime IOP reduction was statistically different in the three prostaglandin groups. Furthermore, a trial by Orzalesi et al. [92] compared the 24-h efficacy of latanoprost, travoprost, and bimatoprost in patients with POAG and OHT: all 3 prostaglandins appeared similarly effective in controlling 24-h IOP with greater efficacy seen during the daytime than at night. In another crossover 24-h study, Konstas et al. [18] evaluated evening-dosed latanoprost and bimatoprost in patients with POAG and reported that 24-h efficacy was statistically better with bimatoprost than latanoprost, although the overall IOP difference between groups was small. In a parallel arms study, Yildirim et al. [93] randomized 48 patients with newly diagnosed open-angle glaucoma to treatment with latanoprost $(n=17)$, travoprost $(n=15)$, and bimatoprost $(n=16)$ over 8 weeks. The mean untreated 24-h IOP for the groups were $22.3 \mathrm{mmHg}, 23.4 \mathrm{mmHg}$, and $22.6 \mathrm{mmHg}$, respectively $(P>0.05)$. Although the mean $24-\mathrm{h}$ treated IOP for each group is not reported, the authors mention that in patients treated with travoprost, IOP was reduced by 8.7 and $8.1 \mathrm{mmHg}$ at the 08:00 am and 10:00 am time points, respectively. At the same time points, patients treated with latanoprost demonstrated smaller IOP reductions (4.8 and $5.3 \mathrm{mmHg}$, respectively). Patients treated with bimatoprost also exhibited less IOP reduction (5.5 and $4.9 \mathrm{mmHg}$ ) than with travoprost. Pressure differences at all other time points were not statistically significant. According to this investigation, IOP reduction at 8:00 am and $10: 00 \mathrm{am}$ in the travoprost group was significantly greater that with the other two prostaglandins. In contrast to these results, a diurnal study by Gandolfi et al. [94] showed that bimatoprost was superior to latanoprost at two time points, noon and 4:00 pm. In another diurnal study by DuBiner et al. [95], bimatoprost provided a greater mean reduction in IOP than latanoprost at all time points during the day $(8: 00 \mathrm{am}$, noon, 4:00 pm, and 8:00 pm) after one month of treatment.

More recently, the circadian ocular hypotensive effect of travoprost with the SofZia preservative was reported [68]. In a prospective, open-label study performed in a sleep lab with 40 participants with open-angle glaucoma or OHT, it was shown that travoprost significantly lowered mean diurnal and nocturnal IOP levels from baseline after 1 month of therapy. Moreover, the investigators examined the maintenance of the ocular hypotensive effect after three travoprost doses were omitted. They found that mean IOP remained significantly lower than baseline both during the daytime and nighttime. It is worth noting that in this study, travoprost reduced only modestly daytime IOP (16\%), nighttime IOP (6\%), and mean 24-h IOP $(12 \%)$ in the habitual position. This may be attributed to the relatively low baseline pressure (sitting daytime IOP: $18.1 \pm 3.9 \mathrm{mmHg}$, supine nighttime IOP: $20.6 \pm 3.6 \mathrm{mmHg}$ ).

A recent crossover study compared the $24-\mathrm{h}$ efficacy of preservative-free tafluprost versus branded, preserved latanoprost in patients with POAG or OHT [57]. Both medications significantly reduced the untreated mean IOP (24.9 mmHg). When directly compared, preservative-free tafluprost exhibited similar mean 24-h efficacy with latanoprost (17.8 vs. $17.7 \mathrm{mmHg} ; P=0.417$ ). In this study, latanoprost demonstrated significantly lower 24-h trough pressure (15.9 vs. $16.3 \mathrm{mmHg}$; 
$P=0.041)$ whereas preservative-free tafluprost provided significantly lower 24-h fluctuation (3.2 vs. $3.8 \mathrm{mmHg} P=0.008$ ).

Although in general the reported 24-h efficacy of prostaglandins is clinically comparable, some data suggest that travoprost and bimatoprost may provide more consistent IOP reduction over the 24-h period [6]. Specifically, travoprost has been shown to be more effective than latanoprost [96] and overall travoprost and bimatoprost appear to reduce nighttime IOP more consistently than latanoprost [68, 96-98]. Therefore, patients on travoprost or bimatoprost may be more likely to achieve a lower target 24-h pressure [6, 55, 99]. Although it remains to be established if such statistically significant 24-h IOP differences are also clinically meaningful, controlled trials employing single pressure measurements have shown that $1 \mathrm{mmHg}$ of further IOP reduction can reduce the risk of glaucoma progression by approximately $10 \%[100,101]$. Taking these facts in account, it can be assumed that there is even more value in maintaining a lower target IOP over the full 24-h period.

Recently, Tung et al. [102], in a sleep laboratory study, investigated the 24-h efficacy of the recently available $0.01 \%$ bimatoprost solution in a cohort of patients with either POAG $(n=3)$ or OHT $(n=13)$. In contrast to the standard $0.03 \%$ bimatoprost solution, the new formulation was developed with the aim of reducing the occurrence and severity of ocular hyperaemia while broadly maintaining the efficacy of the $0.03 \%$ solution. To achieve this, the $0.01 \%$ formulation had to contain a higher concentration of the preservative benzalkonium chloride compared to the standard $0.03 \%$ bimatoprost formulation ( $0.2 \mathrm{vs} .0 .05 \mathrm{mg} / \mathrm{mL}$ ). This was deemed necessary to enhance corneal penetration and intraocular bioavailability of the new formulation. Although the authors do not report the mean 24-h efficacy of the study medication, they demonstrate a mean habitual IOP reduction of $21.7 \%$ during the day and $10.2 \%$ during the night.

There is generally limited information on the 24-h efficacy of prostaglandins in other glaucomas. Ishibashi et al. [103] investigated the effect of latanoprost on circadian sitting IOP in patients with NTG. They found that latanoprost offered a statistically significantly, but relatively small, mean $24-\mathrm{h}$ IOP reduction $(12.5 \%)$ in this series of patients with relatively low baseline IOP (mean IOP at baseline: $13.9 \mathrm{mmHg}$ ). In a crossover, investigator-masked 24-h study with newly diagnosed, previously untreated patients with NTG, evening-dosed latanoprost and bimatoprost exhibited similar efficacy over the $24-\mathrm{h}$ period (16\% reduction from baseline) and for each time-point measured [104]. A crossover study by Costagliola et al. [105] showed that the 24-h efficacy of latanoprost is superior to that of timolol $0.5 \%$ dosed twice daily in patients with NTG.

Considering the chronic, insidious nature of glaucomatous damage and the possibility that suboptimal long-term IOP control may increase the chances of disease progression [30, 83, 84], knowledge of the long-term 24-h efficacy of all medications should be considered highly relevant. Topical therapy for glaucoma should be effective in maintaining a sustained IOP reduction over the long-term [106, 107]. Clinical trials with latanoprost monotherapy have established a long-lasting daytime hypotensive effect with little evidence of tachyphylaxis for up to 4 years [106-110]. Recently, a 24-h investigation by Riva et al. [28] showed that a relatively high proportion $(82 \%)$ of previously untreated patients with POAG reached and maintained a predetermined, individualized target IOP 
reduction between 20 and 30\% with travoprost monotherapy during a 5-year follow-up period that included annual 24-h measurements. This long-term result compares well with the reported short-term 24-h efficacy of travoprost monotherapy [6]. Similarly, a multicenter study on patients with POAG treated with latanoprost monotherapy reported satisfactory IOP control in the vast majority of their patients (86\%), but this was with a shorter 2-year follow-up [111].

\section{Timolol Maleate}

To date there has been very little published 24-h evidence on other beta-blockers, except timolol maleate. Timolol is a beta-adrenergic blocker that has been used as an IOP-reducing medication since 1979. Currently, it is available both as a hydrogel formulation $(0.1 \%$ or $0.5 \%$ ) administered once daily and an ophthalmic solution $(0.25 \%$ or $0.50 \%)$ typically administered twice daily.

In a 24-h study, Konstas et al. [7] investigated the efficacy of timolol over $24 \mathrm{~h}$ and reported a mean circadian efficacy ranging from $10 \%$ to $25 \%$ in patients with POAG. In a subsequent 24-h study, Orzalesi et al. [10] evaluated the ocular hypotensive effect of timolol in patients with POAG and OHT and established that the nocturnal efficacy was only about half the daytime efficacy. Quaranta et al. [85] consolidated previous evidence and also documented a greater daytime IOP reduction and a smaller, yet still significant, nighttime reduction with timolol. In contrast, Liu et al. [56] compared the efficacy of once-daily timolol gel-forming solution and latanoprost and found that latanoprost, but not timolol, reduced the nocturnal IOP in patients with early glaucoma or OHT. In that study both medications demonstrated similar daytime efficacy. Timolol $0.5 \%$ solution has been shown to achieve a mean 24-h IOP reduction of between $19 \%$ and $24 \%$ from untreated baseline [6, 85]. Although its efficacy tends to be reduced at nighttime, cumulative evidence suggests that its ocular hypotensive effect persists clinically throughout the 24 -h cycle $[6,7,10,50,51,74,85,112]$. As beta-blockers exert their ocular hypotensive effect by reducing aqueous humor production, the weaker nocturnal efficacy of timolol has been attributed to the lower rate of aqueous synthesis at night $[113,114]$.

Timolol gel-forming solutions have been developed in an attempt to extend the duration of its action allowing for once-daily administration, while at the same time improving the systemic safety profile of timolol. Moreover, potential clinical advantages of once-daily timolol gel instillation may include enhancement of adherence and reduced exposure to preservatives. A multicenter daytime study by Shedden et al. [112] compared the efficacy and tolerability of $0.5 \%$ timolol maleate ophthalmic gel-forming solution and $0.5 \%$ timolol ophthalmic solution in adults with POAG or OHT. In this trial, IOP measurements were performed at trough (before the morning instillation) and peak ( $2 \mathrm{~h}$ after instillation) efficacy. The gel-forming solution administered once daily in the morning was just as efficacious as the timolol ophthalmic solution administered twice daily. In a subsequent complete 24-h assessment of the two formulations, Konstas et al. [74] reported similar 24-h efficacy in previously untreated patients with either POAG or XFG. This observation was further supported in a crossover study with naive patients with POAG conducted by Quaranta et al. [51], who documented comparable 24-h efficacy between twice-daily timolol $0.5 \%$ solution and timolol $0.1 \%$ ophthalmic gel administered in the morning. 


\section{Topical Carbonic Anhydrase Inhibitors}

This class of medications comprises two drugs with virtually identical efficacy and tolerability profiles, namely dorzolamide hydrochloride $2 \%$ solution and brinzolamide $1 \%$ suspension [115-117]. Dorzolamide hydrochloride $2 \%$ was the first topical carbonic anhydrase inhibitor to become commercially available in 1995 for the treatment of POAG or OHT. It has been reported to reduce IOP from $16 \%$ to $26 \%$ as monotherapy when dosed three-times daily [6, $10,85,118,119]$. Subsequently, a number of 24-h efficacy studies have shown that contrary to timolol, dorzolamide is more efficacious during the night. First, Orzalesi et al. [10] compared dorzolamide, timolol and latanoprost in a 24-h IOP trial and found that mean IOP was significantly lower with latanoprost whereas there was no significant difference between dorzolamide and timolol with regard to mean 24-h IOP. They also reported that dorzolamide was more efficacious than timolol during the night (midnight and 3:00 am), while latanoprost did lower nighttime IOP more than dorzolamide. In another 24-h investigation [13], dorzolamide was added to timolol in patients with POAG or XFG chronically treated with timolol; following the addition of dorzolamide as adjunctive therapy to timolol maleate there was a significant reduction in IOP $(P<0.05)$ at all time points. Contrary to the report by Orzalesi et al. [10], a report by Quaranta et al. documented dorzolamide to be as effective as latanoprost during nighttime (10:00 pm to 6:00 am) and less effective than timolol or latanoprost during daytime (6:00 am to 8:00 pm) [85].

A meta-analysis by Stewart et al. [6] confirmed the observation that carbonic anhydrase inhibitors may be the only class of medications with better nighttime than daytime efficacy. Specifically, this meta-analysis reported that dorzolamide reduced mean IOP by $16 \%$ at daytime and $21 \%$ at nighttime. The enhanced nighttime efficacy of dorzolamide contrasts to the reduced nighttime efficacy of timolol. This characteristic dissimilarity may be attributed to the different mode of action of these medications: although both exert their ocular hypotensive effect by reducing the synthesis of aqueous humor, dorzolamide does so by inhibiting the activity of carbonic anhydrase, while timolol blocks beta-adrenergic receptors [118]. The normally occurring reduction in endogenous circulating catecholamines at night may explain the decreased nocturnal efficacy of beta-blockers [120]. Vanlandingham et al. [119] evaluated the effect of dorzolamide on aqueous humor dynamics in normal subjects during sleep using a fluorophotometry technique and observed that dorzolamide suppressed nighttime flow in the sleeping eye by only $9 \%$, which is significantly less than the nighttime effect of acetazolamide (24\% suppression).

A daytime comparison of twice-daily versus three-times-daily administration of dorzolamide as adjunctive therapy to prostaglandins was performed by Lupinacci et al. [64]. The two regimens were equally efficacious, except for a single time-point at 6:00 pm where the three-times-daily dosage offered a significantly lower IOP ( -4.7 vs. $-2.3 \mathrm{mmHg}$ ).

\section{Brimonidine}

Brimonidine $0.2 \%$ was released commercially in late 1996 . It is a highly selective $\alpha 2$-adrenergic agonist. Similarly to dorzolamide, it is labeled for use three-times a day, but it may be 
administered twice daily. Brimonidine $0.2 \%$ dosed twice daily achieves a mean 24-h IOP reduction of $14 \%$ to $19 \%[6,86,121]$. Quaranta et al. [85] reported that the 24-h IOP reduction pattern with brimonidine was similar to dorzolamide at daytime (8:00 am to $8: 00 \mathrm{pm})$ and to timolol at nighttime $(10: 00 \mathrm{pm}$ to 6:00 am). However, in another 24-h crossover study, Orzalesi et al. [21] documented brimonidine to have minimal efficacy during the late nighttime and early morning period (3:00 am and 6:00 am) with no significant IOP difference from untreated baseline. This reduced nighttime hypotensive efficacy was comparable to that reported for timolol [14, 122]. Furthermore, Liu et al. [123] in an open-label 24-h study performed in a sleep laboratory with 15 patients with open-angle glaucoma or OHT, observed that brimonidine given three-times daily reduced the mean daytime IOP by $12.5 \%$ but had no demonstrable IOP-lowering effect during the night.

In a crossover double-masked trial, Konstas et al. [14] evaluated the 24-h efficacy of brimonidine $0.2 \%$ administered twice, or three-times daily versus timolol maleate $0.5 \%$ given twice daily in patients with POAG. The mean 24-h IOP for brimonidine twice daily and three-times daily was $19.2 \mathrm{mmHg}$ and $18.0 \mathrm{mmHg}$, respectively, whereas for timolol it was $17.7 \mathrm{mmHg}$. The differences for all 24-h comparisons were significant. Moreover, pair-wise comparisons showed that thrice-daily brimonidine or twice-daily timolol reduced IOP more than twice-daily brimonidine at every time point after 10:00 am. In contrast, thrice-daily brimonidine and twice-daily timolol were statistically similar over the 24-h period, except at 4:00 pm when timolol maleate performed significantly better. This group of investigators also reported that three-times-daily brimonidine provided significantly better late afternoon and early nighttime efficacy than twice-daily dosing. In a subsequent double-masked, crossover multicenter daytime study, Stewart et al. [121] compared brimonidine $0.2 \%$ versus dorzolamide $2 \%$ both administered three-times daily, and found similar mean IOP reduction at both trough and peak efficacy time points. Similar results were reported in a double-masked crossover diurnal study by Whitson et al. [124].

\section{4-H EFFICACY OF FIXED AND UNFIXED COMBINATION THERAPIES}

Cumulative evidence from clinical trials clearly indicates that the majority of glaucoma patients need more than one medication to reach target IOP. The Collaborative Initial Glaucoma Treatment Study (CIGTS) found that about $75 \%$ of patients needed 2 or more medications to reach the predetermined target pressure [125]. Compared to concomitant administration of glaucoma medications, fixed combinations offer several potential advantages such as ease of use, decreased exposure to preservatives, improved adherence and avoidance of medication washout [126]. Several studies have compared the efficacy and safety of fixed combinations versus monotherapies, or the concomitant use of individual medications. Unfortunately, most published studies have assessed the diurnal efficacy of fixed combinations, with a few daytime IOP measurements, rather than the complete 24-h efficacy.

This section summarizes the existing evidence on the 24-h ocular hypotensive effect of both fixed and unfixed combinations. 
Pilocarpine containing combinations were not reviewed. As evidenced in the following paragraphs, very few trials were carried out with the primary objective of evaluating the 24-h efficacy of unfixed combinations, except when comparisons with fixed combinations were made. Similarly, although there are few systematic reviews and meta-analyses that have examined the efficacy of combination therapies in glaucoma [70, 127, 128], only one has specifically focused on 24-h efficacy [6] and another on 24-h IOP fluctuation [77].

\section{Combinations of Prostaglandin Analogs with Beta-Blockers}

\section{Combination of Latanoprost and Timolol}

A meta-analysis of clinical trials on the 24-h efficacy of IOP-lowering medications reported an average reduction of 33\% for the LTFC [6].

A placebo-controlled crossover study was carried out in 20 patients with OHT with a follow-up of 1 month [20]. The LTFC was more efficacious than placebo in reducing 24-h IOP: the ocular hypotensive effect was in favor of LTFC both at daytime (10:00 am to $10: 00 \mathrm{pm})$ and at nighttime $(5.6$ and $3.1 \mathrm{mmHg}$, respectively).

In a 2-month, crossover trial, Konstas et al. [58] compared the circadian efficacy of timolol dosed twice daily and LTFC dosed in the evening in 34 patients with POAG. Pressure was measured every $4 \mathrm{~h}$ in the sitting position with a Goldmann tonometer. LTFC was more efficacious than timolol at all time points. Mean IOP was reduced from $25 \mathrm{mmHg}$ at baseline to 16.4 and $19.3 \mathrm{mmHg}$ with LTFC and timolol, respectively. These results were later confirmed in a similar crossover 24-h IOP and blood pressure trial investigating LTFC and timolol in eyes with POAG or OHT [129]. The 24-h efficacy of LTFC compared with that of latanoprost when both medications are administered in the evening was investigated in a 2-month crossover trial in a group of 37 patients with POAG [19]. The sitting IOP was measured with a Goldmann tonometer every $4 \mathrm{~h}$. The baseline IOP was reduced from 24.2 to $16.7 \mathrm{mmHg}$ and $19.2 \mathrm{mmHg}$ with LTFC and latanoprost, respectively. Both the mean and the individual time point IOP reduction were significantly lower with LTFC. A 3-month, parallel arms, randomized clinical trial investigated the efficacy of LTFC given in the morning and bimatoprost given at night over a period of $24 \mathrm{~h}$ [67]. These investigators reported that both regimens were equally efficacious in reducing 24-h IOP and no significant difference was detected in mean diurnal or nocturnal pressures.

\section{Combination of Travoprost and Timolol}

In a 4-month crossover study, the efficacy of morning versus evening administration of TTFC was compared in 32 patients with either POAG or XFG [75]. The IOP was measured with Goldmann tonometry. Mean baseline 24-h IOP was $27.7 \mathrm{mmHg}$ and both morning and evening dosing of the TTFC resulted in a highly significant IOP reduction at all time points. Compared to morning dosing, the evening dosing of TTFC was associated with significantly lower 24-h IOP (18.4 vs. $19.2 \mathrm{mmHg}$ ) and reduced 24-h fluctuation ( 3.8 vs. $5.1 \mathrm{mmHg}$ ). More recently, the 24-h efficacy of LTFC preserved with benzalkonium chloride and TTFC preserved with Polyquad $^{\circledR}$ (Alcon Laboratories) when both are administered in the evening was compared in glaucoma patients insufficiently controlled with latanoprost monotherapy [130]. In this observer-masked, crossover, 3-month study, the investigators employed Goldmann and Perkins tonometers to evaluate 42 patients 
with open-angle glaucoma chronically treated with latanoprost who exhibited daytime IOP $>20 \mathrm{mmHg}$ on two separate occasions. The mean latanoprost-treated baseline IOP was $21.5 \pm 1.6 \mathrm{mmHg}$. Both fixed combinations significantly reduced the IOP at each time-point, as well as the mean, peak, and 24-h IOP fluctuation. However, the TTFC preserved with Polyquad provided significantly lower mean 24-h IOP $(18.9 \pm 2.2$ vs. $19.3 \pm 2.3 \mathrm{mmHg} ; P=0.004)$ and significantly lower IOP at $6: 00 \mathrm{pm} \quad(18.6 \pm 2.5 \quad$ vs. $19.5 \pm 2.7 \mathrm{mmHg} ; P<0.001)$.

\section{Combination of Bimatoprost and Timolol}

Konstas et al. [76] evaluated the efficacy of the fixed combination of bimatoprost and timolol (BTFC) on 24-h IOP. These investigators included 60 patients with XFG in a three-arm, crossover trial. The mean untreated baseline IOP was $29.0 \mathrm{mmHg}$. Patients were first treated with bimatoprost monotherapy for 6 weeks and were then randomized to morning, or evening administration of BTFC for another 3 months. Compared to morning dosing, evening dosing of BTFC was statistically more efficacious: the mean 24-h IOP reduction with evening versus morning dosing was 10.2 and $9.8 \mathrm{mmHg}$, respectively $(P=0.005)$. Both morning and evening dosing of BTFC was more efficacious than bimatoprost monotherapy at all time points. In a more recent investigator-masked, crossover, 3-month trial, the 24-h efficacy of evening-dosed BTFC was investigated as first-choice therapy compared with a standard first-choice therapy (latanoprost) in 37 patients with high-pressure XFS or XFG [131]. The mean untreated 24-h IOP was $31.1 \mathrm{mmHg}$. At the end of the 3-month period BTFC reduced mean 24-h IOP significantly more than latanoprost (18.9 vs. $21.2 \mathrm{mmHg} ; P<0.001)$. Additionally, BTFC was significantly more efficacious than latanoprost at every time point for the mean peak and trough 24 -h pressure $(P<0.001)$.

\section{Combinations of Carbonic Anhydrase Inhibitors with Beta-Blockers}

\section{Combination of Dorzolamide and Timolol}

A meta-analysis of clinical trials on the 24-h efficacy of IOP-lowering medications reported an average reduction of $26 \%$ with the DTFC compared to baseline [6]. It is noteworthy that to date several investigators have evaluated the 24-h efficacy of DTFC. A parallel arms, randomized, 2-month trial compared DTFC with timolol in a large cohort of 232 patients with open-angle glaucoma or OHT [52]. DTFC significantly reduced IOP at all time points when compared to baseline. Compared to timolol monotherapy, DTFC therapy resulted in a statistically significant lower mean daytime IOP and at two time points: 10:00 am and 2:00 pm.

In a 6-week crossover study of patients with POAG and OHT, Konstas et al. [16] compared the 24-h efficacy of latanoprost versus DTFC. The mean circadian IOP for latanoprost and DTFC was $15.9 \pm 2.3$ and $15.3 \pm 2.0 \mathrm{mmHg}$, respectively $(P=0.05)$. Although there was no significant IOP difference at other time-points, at the 10:00 am time-point pressures with latanoprost and DTFC were $16.6 \pm 3.1$ and $14.6 \pm 2.7 \mathrm{mmHg}, \quad$ respectively $\quad(P<0.006)$. Quaranta et al. [60], in a 3-month crossover trial, compared the 24-h efficacy of DTFC and latanoprost in a group of 27 previously untreated patients with POAG. The authors found a significant difference in mean circadian IOP reduction between treatments $(1.3 \mathrm{mmHg})$ in favor of DTFC when the fixed combination was employed as first-choice therapy. Konstas et al. [61] compared the short-term versus the mid-term 24-h efficacy 
of DTFC and latanoprost in a six-month crossover study that included 53 patients with POAG or OHT. The mean 24-h baseline IOP (25.2 $\mathrm{mmHg}$ ) was reduced to $18.1 \mathrm{mmHg}$ and $18.3 \mathrm{mmHg}$ with DTFC and latanoprost, respectively. With the exception of one time-point (10:00 am), this study documented similar 24-h efficacy between the two medications at 2 and 6 months.

In another crossover study, Orzalesi et al. [21] investigated the circadian IOP characteristics of 20 patients with POAG or OHT who were treated with DTFC, latanoprost, or brimonidine. This study documented greater efficacy for DTFC compared with brimonidine at 3:00 am, 9:00 am, 3:00 pm, and 6:00 pm. Furthermore, DTFC was also more efficacious than latanoprost at 9:00 am. Eren et al. [132] conducted a double-masked, 6-week, crossover 24-h study employing Goldmann tonometry to compare DTFC and LTFC in 33 washed-out POAG patients. The mean untreated 24-h IOP was $25.1 \mathrm{mmHg}$. In this study, LTFC was more efficacious than DTFC in lowering the mean 24-h IOP (16.3 vs. $17.3 \mathrm{mmHg}$ ) and the peak 24-h IOP (18.5 vs. $19.9 \mathrm{mmHg}$ ).

The 24-h IOP-lowering effect of DTFC was compared to that of the timolol-brimonidine fixed combination in a crossover trial [133]. DTFC was more effective and the difference (mean $-0.7 \mathrm{mmHg} ; 95 \% \mathrm{CI}-1.0$ to -0.3 ; $P<0.001)$ reached statistical significance.

\section{Combination of Brinzolamide and Timolol}

There is limited information available on the 24-h efficacy of the brinzolamide/timolol fixed combination. Recently, the 24-h IOP reduction obtained with the brinzolamide/timolol and the brimonidine/timolol fixed combination as adjunctive therapies to travoprost was investigated in an observer-masked, crossover 24-h study in patients with POAG and XFG insufficiently controlled with travoprost [69]. These authors found that the brinzolamide/timolol fixed combination provided significantly better mean 24-h IOP control (17.2 mmHg) than the brimonidine/timolol fixed combination (18.0 $\mathrm{mmHg}$. In particular, the brinzolamide/timolol fixed combination provided superior IOP control in late afternoon and in the night $(6: 00 \mathrm{pm}$ till 2:00 am; $P \leq 0.036)$.

\section{Combinations of Carbonic Anhydrase Inhibitors with a Prostaglandin Analog: Dorzolamide/Brinzolamide and Latanoprost}

Three studies have examined the 24-h efficacy of dorzolamide when added to latanoprost. Tamer et al. [62] conducted a crossover trial with 36 patients with POAG treated with latanoprost monotherapy and found an additional ocular hypotensive effect of $3.2 \mathrm{mmHg}$ over $24 \mathrm{~h}$ when dorzolamide was added to latanoprost. Timolol was less effective over $24 \mathrm{~h}$ when added to latanoprost (2.6 mmHg). Importantly, when all time points were analyzed in this trial, dorzolamide was superior to timolol in five out of the eight time points evaluated. In a crossover trial, Nakamura et al. [63] compared the adjunctive 24-h efficacy of dorzolamide versus that of brinzolamide when both are added to latanoprost. Compared to the latanoprost baseline, both carbonic anhydrase inhibitors resulted in a significantly reduced IOP. No difference in efficacy between the two drugs could be established. Finally, a crossover study by Konstas et al. [65] examined the 24-h IOP-lowering effect of dorzolamide or brimonidine purite when added to latanoprost. Mean latanoprost-treated 
circadian IOP $(19.0 \mathrm{mmHg})$ was further reduced to $16.9 \mathrm{mmHg}$ and $16.8 \mathrm{mmHg}$ with brimonidine purite and dorzolamide, respectively.

\section{Combination of an Alpha-2 Agonist and a Beta-Blocker: Brimonidine and Timolol}

To date there is limited 24-h IOP evidence for the combination of brimonidine and timolol in patients with glaucoma. A 6-month crossover study has evaluated the 24-h IOP-lowering effect of the fixed combination of brimonidine and timolol versus the concomitant administration of the 2 components in a cohort of 28 patients with POAG or OHT. Both the fixed and unfixed combination reduced the baseline mean untreated 24-h IOP of 24.6 to $19.2 \mathrm{mmHg}$ [54]. This reduction over $24 \mathrm{~h}(22 \%)$ was less than anticipated or reported with other fixed combinations.

\section{Combination of an Alpha-2 Agonist and a Carbonic Anhydrase Inhibitor}

Recently, the first fixed combination without a $\beta$-blocker (brinzolamide 1\%/brimonidine tartrate $\quad 0.2 \% \quad$ ophthalmic suspension, Simbrinza $^{\mathrm{TM}}$ (Alcon), was approved in the USA and in several other countries for the treatment of open-angle glaucoma and OHT. The new combination is labeled for three-times-daily administration and its 24-h efficacy remains to be determined.

\section{Conclusions}

Table 1 summarizes the average 24-h efficacy of commonly used antiglaucoma drug combinations. Several fixed combinations are currently available, with a potent IOP-lowering efficacy, which appears to be fairly uniform throughout the $24 \mathrm{~h}$. However, few high-quality trials have assessed the 24-h efficacy of combined antiglaucoma therapy. These mostly short-term studies only constitute a small portion of the literature on the medical therapy of glaucoma. Given the significant time-dependent variation of drug efficacy and the fluctuation of 24-h IOP, and despite the obvious difficulties in conducting such studies (higher cost, limited resources, difficulties in enrolment and logistics, etc.), more effort should be devoted to adequately document the circadian efficacy of combined antiglaucoma therapy.

\section{4-H IOP CONTROL WITH LASER TRABECULOPLASTY}

Since its development, argon laser trabeculoplasty (ALT) has evolved as a popular adjunctive or sometimes even initial therapy option in the management of open-angle glaucoma [134], either as an intervention before the instigation of medical therapy [135], or when greater pressure reduction is needed to prevent further glaucoma progression in medically treated patients [136]. In the late 1990s, Latina and coworkers [137] reported promising results with a new laser technique called selective laser trabeculoplasty (SLT). Ever since the initial report, SLT has become a popular treatment option worldwide and its use has been advocated as an alternative to ALT. Although the exact mechanism by which trabeculoplasty (ALT and SLT) decreases IOP remains controversial [138], the common view is that the laser induces structural, biological, and biochemical changes within the trabecular meshwork that result in a meaningful enhancement of outflow facility. Prospective 
Table 1 Summary of available evidence on the 24-hour efficacy of fixed combination therapies

\begin{tabular}{|c|c|c|c|c|}
\hline \multirow[t]{2}{*}{ Therapies } & \multicolumn{3}{|c|}{ Intraocular pressure reduction (\%) } & \multirow[t]{2}{*}{ Reference(s) } \\
\hline & $\begin{array}{l}\text { Average } \\
\text { 24-h }\end{array}$ & Diurnal & Nocturnal & \\
\hline Latanoprost/timolol & $24-34$ & $28-35$ & $16-33$ & {$[12,15,16,19,20,56,58,67,88,129]$} \\
\hline Travoprost/timolol & 33 & 35 & 31 & {$[75]$} \\
\hline Bimatoprost/timolol & 35 & 38 & 32 & {$[76,131]$} \\
\hline Dorzolamide/timolol & $25-28$ & 30 & $20-26$ & {$[13,16,21,52,60,61]$} \\
\hline Brimonidine/timolol & 22 & 22 & 22 & {$[54]$} \\
\hline
\end{tabular}

Percentages of IOP reduction from untreated baseline are reported as ranges of means. Figures are derived from the trials discussed in this review

and retrospective studies indicate that both ALT and SLT demonstrate similar efficacy in terms of IOP control [139-141], but SLT preserves the trabecular tissue architecture and may be repeated with greater success than ALT [142-144].

Although the IOP-lowering efficacy of trabeculoplasty during office hours [145] and the effect on long-term variation of IOP has been well documented previously [146], information is currently scant on the 24-h efficacy of laser trabeculoplasty [147]. Agarwal and coworkers [148] analyzed the long-term effect of ALT on the circadian IOP characteristics of Indian patients. The authors performed $360^{\circ}$ ALT in a group of previously untreated POAG patients (40 eyes of 21 patients) and a group of patients with POAG who were on medical therapy for more than 1 year (39 eyes of 21 patients). Goldmann tonometry was performed every $3 \mathrm{~h}$ from 4:00 am until 10:00 pm. In the previously untreated group, mean IOP was reduced from $25.8 \pm 3.4$ to $18.1 \pm 3.2 \mathrm{mmHg}(-29.8 \%)$ after 5 years of follow-up. In the previously medically treated group, mean IOP was reduced from $26.1 \pm 3.2$ to $22.7 \pm 3.9 \mathrm{mmHg}(-13 \%)$ at the 5 -year follow-up time-point. The circadian IOP fluctuation decreased from $7.9 \pm 1.4 \mathrm{mmHg}$ at baseline to $3.6 \pm 1.3 \mathrm{mmHg}$ after 5 years of follow-up in the previously untreated group, and from $7.7 \pm 1.4 \mathrm{mmHg}$ at baseline to $5.8 \pm 1.8 \mathrm{mmHg}$ after 5 years in the medically treated group. The authors concluded that in this population of patients with POAG with a heavily pigmented trabecular meshwork, ALT appears significantly more effective when employed as primary therapy.

The ability of ALT to improve the circadian IOP characteristics was first shown by Greenidge et al. [149] who employed applanation tonometry to investigate the 24-h IOP characteristics of 25 patients with glaucoma. The investigators compared 24-h pre-treatment IOP data with IOP curves obtained $24 \mathrm{~h}$ and 8 weeks after laser therapy. Topical medications were not modified during the period of this study. It is worth noting that a pressure elevation greater than $5 \mathrm{mmHg}$ occurred in $46 \%$ of treated patients. In this study, IOP fluctuation was referred to as 'IOP irregularity' (sic) and was defined as the standard deviation of all measurements in the 24-h cycle. Following ALT, a significant decrease in mean (22\%), range (30\%), fluctuation (25\%), and peak 24-h IOP (25\%) was found. Interestingly, the 
authors noted that some patients, despite having a minimal IOP reduction at a reference office-hour measurement (1:00 pm), demonstrated more favorable overall circadian IOP characteristics following ALT. However, one of the study limitations was that night measurements were taken in the sitting position, after the patient was woken up.

In a 24-h study performed in a sleep laboratory, Lee and coworkers [150] investigated the 24-h efficacy of ALT in 28 eyes of 18 patients with open-angle glaucoma whose target IOP was not reached with topical medical therapy. Twenty-four-hour pressure was monitored with a pneumotonometer every $2 \mathrm{~h}$ in the sitting position (at daytime) and the supine position (during the day and night) before and approximately 2 months after laser therapy. Baseline mean daytime sitting IOP, mean nocturnal supine IOP, and mean habitual 24-h IOP was $17.3 \pm 2.9,24.7 \pm 5.5$, and $19.8 \pm 3.4 \mathrm{mmHg}$, respectively. Following laser therapy, mean IOP measurements were: $16.6 \pm 3.5,22.8 \pm 5.0$, and $18.7 \pm 3.6 \mathrm{mmHg}$, respectively. According to the results of this study, laser therapy did not meaningfully alter daytime IOP. In contrast, mean 24-h, peak, and habitual IOP were all significantly reduced. The investigators concluded that laser therapy exhibited minimal daytime, but significant nocturnal efficacy. Thus, they proposed that even when patients exhibit a poor response to laser therapy during office hours there might be a benefit from laser during the nighttime. Nonetheless, it remains unclear why this 24-h study did not detect the daytime efficacy previously reported by other investigators [1, 148, 149].

Nagar et al. [151] studied the effect of SLT on diurnal tension curves in patients with OHT and POAG. Forty patients were included and randomized to receive $360^{\circ}$ SLT treatment or latanoprost. The authors evaluated the diurnal pre-treatment IOP as well as post-laser pressures after 3 days, 1 week, 1 month, and 4 to 6 months. The IOP was measured at $8.00 \mathrm{am}$, $11.00 \mathrm{am}, 2.00 \mathrm{pm}$, and $6.00 \mathrm{pm}$ (Goldmann applanation tonometry). The difference between peak and trough IOP was considered as the diurnal fluctuation. Success was defined as a $50 \%$ decrease in IOP fluctuation. IOP decrease was similar in both groups and IOP reduction at final follow-up visit was $6.2 \pm 0.8 \mathrm{mmHg}$ for the SLT group and $7.8 \pm 0.8 \mathrm{mmHg}$ for the latanoprost group. The IOP fluctuation was reduced in both groups; however, latanoprost was more efficacious (41\% reduction for SLT vs. $64 \%$ for latanoprost). Moreover, latanoprost resulted in higher success rates compared to $90^{\circ}$ and $180^{\circ}$ SLT treatments. The difference in efficacy between latanoprost and $360^{\circ}$ SLT treatment did not reach statistical significance.

Kóthy and coworkers [152] were the first to report the 24-h efficacy of SLT in a group of 26 eyes of 13 patients with POAG who had been washed out of their topical medical therapy. The authors reported that no eye showed evidence of a mean 24-h IOP reduction of $20 \%$ or more. However, the amplitude of $24-\mathrm{h}$ fluctuation was significantly reduced with SLT. The investigators concluded that office time IOP measurements alone might not adequately portray the overall 24-h efficacy of SLT treatment.

Recently, Tojo et al. [153] examined the 24-h effectiveness of SLT in 10 previously treated Japanese patients with NTG employing the Sensimed Triggerfish ${ }^{\circledR}$ contact lens sensor (Sensimed AG). This device consists of a disposable silicone contact lens with a built-in micro-electromechanical system, which measures curvature alterations at the corneoscleral junction induced by IOP 
variations. An antenna mounted around the patient's eye receives the data, which are then transmitted to a recorder. Unfortunately, this system produces arbitrary units, rather than actual pressure values. Using this continuous telemetric platform, the authors established that in patients with NTG, SLT does not reduce mean habitual 24-h IOP or mean diurnal IOP fluctuation, but does reduce nocturnal IOP fluctuation.

\section{4-H EFFICACY OF SURGERY}

IOP reduction remains the mainstay of glaucoma therapy and the conventional stepwise algorithm usually involves medical treatment, then laser trabeculoplasty, and finally surgical techniques. Surgery has been shown to reduce the mean IOP to acceptable safe levels, providing long-term daytime IOP control and optic disc and visual field stability [29, 125, 154-163]. IOP is not a static parameter but instead undergoes dynamic changes. Therefore, implied in the definition of target IOP is a dampening of its cyclic fluctuations throughout the day, as these diurnal variations have been identified as a significant and independent risk factor in glaucomatous progression [5, 8, 9, 34, 84, 155, 156].

Evaluating the 5-year efficacy of trabeculectomy in controlling IOP, Saiz et al. [157] reported a diurnal range of $4.8 \pm 2.5 \mathrm{mmHg}$ for the period between 8:00 am and 6:00 pm, in 14 patients with open-angle glaucoma. Gandolfi et al. [158] documented the diurnal range $(8: 00 \mathrm{am}$ to 6:00 pm with measurements every $2 \mathrm{~h}$ ) to be $10-17 \mathrm{mmHg}$ in patients who underwent a trabeculectomy with adjunctive 5-fluorouracil versus $14-22 \mathrm{mmHg}$ in those patients who had a trabeculectomy without the antimetabolite.

Medeiros et al. [159] compared the mean, peak IOP and daytime diurnal pressure (8:30 am to $5: 00 \mathrm{pm}$ with measurements every $3 \mathrm{~h}$ ) in a group of well controlled with medical therapy patients with glaucoma $(n=30)$ versus a group which underwent trabeculectomy $(n=30)$. The authors did not detect a statistically significant difference in mean IOP between the two groups. In contrast, diurnal fluctuation of IOP was significantly greater in the medically treated group compared to the surgical group $(3.2 \pm 1.5$ vs. $2.2 \pm 1.7 \mathrm{mmHg}$ ). In addition, medically controlled patients had higher peak IOP and demonstrated greater fluctuation after a water-drinking test [159]. In another prospective study, Konstas and coworkers [29] investigated the 24 -h pressure characteristics in patients with advanced open-angle glaucoma who had either undergone successful trabeculectomy or were considered well controlled under maximal medical treatment. Each group consisted of 30 patients matched for daytime IOP (10:00 am). The authors established that successful trabeculectomy provides a statistically lower mean, peak, and fluctuation of 24-h IOP [29]. Specifically, they reported the 24-h fluctuation of IOP to be $2.3 \pm 0.8 \mathrm{mmHg}$ in the surgical group and $4.8 \pm 2.3 \mathrm{mmHg}$ in the medically treated group. A more recent study by Mansouri et al. [160] compared the quality of diurnal IOP control during a water-drinking test in patients with POAG who were either well controlled with latanoprost monotherapy $(n=20)$, or had had successful trabeculectomy $(n=20)$ or deep sclerectomy with collagen implant (DSCI; $n=20$ ). These authors observed that mean IOP during the diurnal period (8:00 am to 5:00 pm) was significantly lower with trabeculectomy $(10.1 \mathrm{mmHg})$ or DSCI (13.7 mmHg) compared with latanoprost monotherapy $(15.7 \mathrm{mmHg})$. Nevertheless, the IOP fluctuation was similar between the surgical and the medical groups. Additionally, during 
the water-drinking test the IOP elevation was significantly greater for the latanoprost-treated group $(5.2 \mathrm{mmHg})$ than the trabeculectomy $(2.4 \mathrm{mmHg})$ and DSCI groups $(3.8 \mathrm{mmHg})$ [160].

Matsuoka et al. [161] investigated the effect of combined trabeculotomy and sinusotomy on the 24-h IOP characteristics in treated patients with open-angle glaucoma [161]. The authors analyzed 14 eyes of 8 patients with office-hour IOP $<17 \mathrm{mmHg}$ who exhibited IOP peaks $>20 \mathrm{mmHg}$ outside office hours. The mean 24-h and peak IOP values were reduced by $15.1 \%$ and $26.3 \%$, respectively, while the 24 -h fluctuation was reduced by $41.3 \%$ after a minimum follow-up period of 3 months following surgery.

Klink et al. [162] investigated the effect of trabeculectomy on the habitual diurnal and nocturnal IOP fluctuations in 35 eyes with open-angle or chronic angle-closure glaucoma. Study patients were treated with $2.0 \pm 1.2$ antiglaucoma medications preoperatively and $0.14 \pm 0.4$ medications postoperatively. The mean follow-up time was $2.1 \pm 1.7$ years. Although the authors do not present mean 24-h pressures, they report that the diurnal fluctuation was significantly reduced from $12.1 \pm 4.2 \mathrm{mmHg} \quad$ preoperatively to $5.6 \pm 2.2 \mathrm{mmHg} \quad$ postoperatively (54\% reduction) and the nocturnal fluctuation was reduced from $7.1 \pm 4.5 \mathrm{mmHg}$ to $3.9 \pm 4.1$ (46\% reduction). The peak diurnal and nocturnal preoperative IOP values $(26.5 \pm 5.9$ and $23.4 \pm 5.2 \mathrm{mmHg}$, respectively) were also significantly reduced $(16.0 \pm 4.4$ and $16.0 \pm 5.4 \mathrm{mmHg}$, respectively).

Recently, Liang et al. [163] described the IOP characteristics of 176 patients with primary angle-closure glaucoma (PACG) who had had trabeculectomy with mitomycin C. Goldmann tonometry measurements were performed from
5:00 am till 10:00 pm in the third postoperative month. The mean IOP was $13.2 \pm 3.7 \mathrm{mmHg}$ and the mean fluctuation was $3.8 \pm 2.1 \mathrm{mmHg}$. It is worth noting that in this surgical cohort, 34 of 176 patients (19\%) exhibited peak IOP readings $>18 \mathrm{mmHg}$. The authors established that IOP fluctuation was positively associated with higher mean and peak IOP and negatively associated with the extent of the bleb area and the presence of microcysts within the bleb.

In another investigation Sihota et al. [43] compared the IOP characteristics of healthy controls $(n=75)$ and patients with newly diagnosed POAG $(n=60)$ or PACG following laser iridotomy $(n=75)$ by performing IOP measurements between 7:00 am and 10:00 pm. The authors documented that IOP fluctuation was significantly greater in the PACG group $(7.7 \pm 3.0 \mathrm{mmHg})$ and in the POAG group $(8.3 \pm 2.6 \mathrm{mmHg})$ compared to normal controls $(4.8 \pm 2.5 \mathrm{mmHg})$. Importantly, in this study morning peaks were more frequent in POAG eyes, whereas afternoon peaks were more common in controls and in the PACG eyes.

\section{THE FUTURE OF 24-H IOP MONITORING IN GLAUCOMA}

It is possible to envisage a day in the future when a resident will ask us: "is it really true that there was a time when glaucoma diagnosis and treatment relied exclusively on IOP measurements once every three months?" The answer will, of course, be: "Yes", because this is what usually happens today. As a matter of fact, we measure IOP infrequently, usually once every time a patient with glaucoma visits the ophthalmologist. If the IOP measurement does not give rise to suspicion, it will be evaluated once again after several months or, in many cases, only after years, at any time during the 
day, according to the patients' convenience and the time of follow-up visit. This reflects what is presently done and that is how it is reimbursed by most healthcare systems and the various insurance companies. Undoubtedly, this cannot be sufficient. There is now comprehensive evidence that IOP fluctuates considerably during the 24-h period and may be quite different in the prone and supine position and relatively high in the early morning hours. This is what we know from evidence emerging from studies of small patient cohorts. But in most cases we can only guess what the real 24-h IOP of the individual patient may be.

Surely, we must strive to acquire a more comprehensive understanding of what is going on with the pressure of the individual patient with glaucoma. We need to check pressures more often than once, ideally outside the 'office hours' and if possible at night when patients are asleep. Few academic centers have the ability and expertise to do this routinely right now. In Germany in-patient diurnal IOP monitoring is being reimbursed and may encompass nighttime IOP measurements if equipment, expertise and logistics allow. This may be one of the reasons why in Germany we tend to see significantly fewer NTG cases than is reported in other parts of the world. Many of those patients diagnosed with NTG demonstrate elevated IOPs outside office hours and, hence, are subsequently classified as POAG cases. This phenomenon has been already highlighted by Gloor and Meier-Gibbons in 1996 [164].

Unfortunately, it should not be assumed that in the future IOP monitoring at the hospital setting is going to be introduced in many countries owing to cost considerations. Even in centers where 24-h monitoring is routinely performed, we measure the IOP only 5 or 6 times and rarely more often. This approach does not resemble systemic blood pressure monitoring.
Indeed, all the IOP measurements obtained within a 24-h curve may only reveal a few minute glimpse of the pressure pathology in a given glaucoma patient. Consequently, for the rest of the 24 -h period the true IOP values remain largely unknown. The same holds true during sports, when blowing a musical instrument or indeed with any other activity that influences IOP.

Thus, new reliable IOP measurement technologies are needed in the future. An IOP-sensitive contact lens or an intraocular implant may soon be clinically widely available. Significant issues remain to be addressed with regard to reliability, cost, and practicality of all new technologies bearing in mind that virtually all IOP evidence currently available from controlled trials and obtained in clinical practice rely on Goldmann technology. Furthermore, even if successful new technologies will not solve all the problems we face, quite the opposite: they will offer new insight into true IOP physiology so that subsequently we may have to change the definition and management of POAG, OHT, and NTG. In fact, Mansouri and Shaarawy [165] have published initial clinical results with a novel wireless ocular telemetry sensor (Sensimed AG) for IOP monitoring in patients with open-angle glaucoma. The device consists of a disposable silicone contact lens with a built-in micro-electromechanical system, which measures alterations in corneal curvature presumably induced by IOP variations. An antenna mounted around the patient's eye receives the data, which are then transmitted to a recorder. Although the authors reported encouraging first results with 24-h ambulatory signal measurements in 15 patients with open-angle glaucoma, a recent study by Holló et al. [166] found that the arbitrary units produced during a 24-h curve with Sensimed measurements had no apparent correlation 
with Goldmann IOP readings in a cohort of patients with open-angle glaucoma who were assessed at baseline and after 3 months of prostaglandin treatment. In addition, the device did not detect any IOP changes induced by the patients' transition from the sitting (wake period) to the supine (sleeping period) position. These authors concluded that the currently available commercial version of the device cannot be used in a clinical setting to monitor the IOP reduction induced by therapy, and has limited value in identifying transient IOP changes. Hopefully in the future there will be more reliable technologies continuously monitoring IOP in millimeters of mercury with Goldmann or equivalent technologies.

\section{ACKNOWLEDGMENTS}

No funding or sponsorship was received for the publication of this article. All named authors meet the International Committee of Medical Journal Editors (ICMJE) criteria for authorship for this manuscript, take responsibility for the integrity of the work as a whole, and have given final approval to the version to be published.

Disclosures. Anastasios G. P. Konstas has received honorariums from (and is a consultant for): Alcon, Allergan and Santen. Luciano Quaranta has received honorariums from (and is a consultant for): Alcon, Allergan, Santen, SOOFT and Visufarma. Banu Bozkurt has received honorariums from (and is a consultant for) Allergan and had congress and travel expenses covered by Alcon and Deva. Andreas Katsanos has received honorariums from Santen and had congress and travel expenses covered by Alcon, Santen and Laboratoires Thea. Julian Garcia-Feijoo is an advisor for Alcon, Bausch and Lomb, Opko,
Ivantis and Istar and has received educational grants from Santen. He has also received fees for trials sponsored by Alcon, Allergan, Pfizer, Sylentis, Bausch and Lomb, Santen, Opko, Glaukos, Ivantis, Istar, InnFocus, Transcend and Sensimed. Luca Rossetti has received travel grants and honorariums from (and is a consultant for): Allergan, Bausch and Lomb, Centervue, MSD, Novartis, Omikron, Santen, Sifi and Visufarma. Tarek Shaarawy has no disclosures to report. Norbert Pfeiffer has received honorariums (and is a consultant for): Alcon, Allergan and Santen. Stefano Miglior has received honorariums from Allergan, SIFI, Alcon, Dorr and had congress and travel expenses covered by Allergan, SIFI and Alcon.

Compliance with Ethics Guidelines. This article is based on previously conducted studies, and does not involve any new studies of human or animal subjects performed by any of the authors.

Open Access. This article is distributed under the terms of the Creative Commons Attribution-NonCommercial 4.0 International License (http://creativecommons.org/licenses/ by-nc/4.0/), which permits any noncommercial use, distribution, and reproduction in any medium, provided you give appropriate credit to the original author(s) and the source, provide a link to the Creative Commons license, and indicate if changes were made.

\section{REFERENCES}

1. Palmberg P. Answers from the ocular hypertension treatment study. Arch Ophthalmol. 2002;120:829-30.

2. Wilensky JT. Diurnal variations in intraocular pressure. Trans Am Ophthalmol Soc. 1991;89:757-90. 
3. Konstas AG, Mantziris DA, Stewart WC. Diurnal intraocular pressure in untreated exfoliation and primary open-angle glaucoma. Arch Ophthalmol. 1997;115:182-5.

4. Wilensky JT. The role of diurnal pressure measurements in the management of open angle glaucoma. Curr Opin Ophthalmol. 2004;15:90-2.

5. Wax MB, Camras CB, Fiscella RG, et al. Emerging perspectives in glaucoma: optimizing 24-hour control of intraocular pressure. Am J Ophthalmol. 2002;133(Suppl):S1-10.

6. Stewart WC, Konstas AG, Nelson LA, Kruft B. Meta-analysis of 24-hour intraocular pressure studies evaluating the efficacy of glaucoma medicines. Ophthalmology. 2008;115:1117-22 (e1).

7. Konstas AG, Mantziris DA, Cate EA, Stewart WC. Effect of timolol on the diurnal intraocular pressure in exfoliation and primary open-angle glaucoma. Arch Ophthalmol. 1997;115:975-9.

8. Asrani S, Zeimer R, Wilensky J, Gieser D, Vitale S, Lindenmuth $\mathrm{K}$. Large diurnal fluctuations in intraocular pressure are an independent risk factor in patients with glaucoma. J Glaucoma. 2000;9:134-42.

9. Hughes E, Spry P, Diamond J. 24-hour monitoring of intraocular pressure in glaucoma management: a retrospective review. J Glaucoma. 2003;12:232-6.

10. Orzalesi N, Rossetti L, Invernizzi $\mathrm{T}$, Bottoli A, Autelitano A. Effect of timolol, latanoprost, and dorzolamide on circadian IOP in glaucoma or ocular hypertension. Invest Ophthalmol Vis Sci. 2000;41:2566-73.

11. Tajunisah I, Reddy SC, Fathilah J. Diurnal variation of intraocular pressure in suspected glaucoma patients and their outcome. Graefes Arch Clin Exp Ophthalmol. 2007;245:1851-7.

12. Konstas AG, Maltezos AC, Gandi S, Hudgins CA, Stewart WC. Comparison of 24-hour intraocular pressure reduction with two dosing regimens of latanoprost and timolol maleate in patients with primary open-angle glaucoma. Am J Ophthalmol. 1999;128:15-20.

13. Konstas AG, Maltezos A, Bufidis T, Hudgins CA, Stewart WC. Twenty-four hour control of intraocular pressure with dorzolamide and timolol maleate in exfoliation and primary open-angle glaucoma. Eye (Lond). 2000;14:73-7.
14. Konstas AG, Stewart WC, Topouzis F, Tersis I, Holmes KT, Stangos NT. Brimonidine $0.2 \%$ given two or three times daily versus timolol maleate $0.5 \%$ in primary open-angle glaucoma. Am J Ophthalmol. 2001;131:729-33.

15. Konstas AG, Nakos E, Tersis I, Lallos NA, Leech JN, Stewart WC. A comparison of once-daily morning vs evening dosing of concomitant latanoprost/timolol. Am J Ophthalmol. 2002;133:753-7.

16. Konstas AG, Papapanos P, Tersis I, Houliara D, Stewart WC. Twenty-four-hour diurnal curve comparison of commercially available latanoprost $0.005 \%$ versus the timolol and dorzolamide fixed combination. Ophthalmology. 2003;110:1357-60.

17. Konstas AG, Kozobolis VP, Lallos N, Christodoulakis E, Stewart JA, Stewart WC. Daytime diurnal curve comparison between the fixed combinations of latanoprost $0.005 \% /$ timolol maleate $0.5 \%$ and dorzolamide $2 \% /$ timolol maleate 0.5\%. Eye (Lond). 2004;18:1264-9.

18. Konstas AG, Katsimbris JM, Lallos N, Boukaras GP, Jenkins JN, Stewart WC. Latanoprost $0.005 \%$ versus bimatoprost $0.03 \%$ in primary open-angle glaucoma patients. Ophthalmology. 2005;112:262-6.

19. Konstas AG, Boboridis K, Tzetzi D, Kalinderis K, Jenkins JN, Stewart WC. Twenty-four-hour control with latanoprost-timolol-fixed combination therapy vs latanoprost therapy. Arch Ophthalmol. 2005;123:898-902.

20. Larsson LI. Effect on intraocular pressure during 24 hours after repeated administration of the fixed combination of latanoprost $0.005 \%$ and timolol $0.5 \%$ in patients with ocular hypertension. J Glaucoma. 2001;10:109-14.

21. Orzalesi N, Rossetti L, Bottoli A, Fumagalli E, Fogagnolo P. The effect of latanoprost, brimonidine, and a fixed combination of timolol and dorzolamide on circadian intraocular pressure in patients with glaucoma or ocular hypertension. Arch Ophthalmol. 2003;121:453-7.

22. Liu JH, Zhang $\mathrm{X}$, Kripke DF, Weinreb RN. Twenty-four-hour intraocular pressure pattern associated with early glaucomatous changes. Invest Ophthalmol Vis Sci. 2003;44:1586-90.

23. Dubiner HB, Sircy MD, Landry $T$, et al. Comparison of the diurnal ocular hypotensive efficacy of travoprost and latanoprost over a 44-hour period in patients with elevated intraocular pressure. Clin Ther. 2004;26:84-91. 
24. Walters TR, DuBiner HB, Carpenter SP, Khan B, VanDenburgh AM, for the Bimatoprost Circadian IOP Study Group. 24-Hour IOP control with once-daily bimatoprost, timolol gel-forming solution, or latanoprost: a 1-month, randomized, comparative clinical trial. Surv Ophthalmol. 2004;49(Suppl 1):S26-35.

25. Bergea B, Bodin L, Svedbergh B. Impact of intraocular pressure regulation on visual fields in open-angle glaucoma. Ophthalmology. 1999;106:997-1004 (discussion: 5).

26. Migdal C, Gregory W, Hitchings R. Long-term functional outcome after early surgery compared with laser and medicine in open-angle glaucoma. Ophthalmology. 1994;101:1651-6 (discussion: 7).

27. Quaranta L, Katsanos A, Russo A, Riva I. 24-hour intraocular pressure and ocular perfusion pressure in glaucoma. Surv Ophthalmol. 2013;58:26-41.

28. Riva I, Katsanos A, Floriani I, et al. Long-term 24-hour intraocular pressure control with travoprost monotherapy in patients with primary open-angle glaucoma. J Glaucoma. 2014;23(8):535-40.

29. Konstas AG, Topouzis F, Leliopoulou O, et al. 24-hour intraocular pressure control with maximum medical therapy compared with surgery in patients with advanced open-angle glaucoma. Ophthalmology. 2006;113(5):761-5 (e1).

30. The Advanced Glaucoma Intervention Study. (AGIS): 7. The relationship between control of intraocular pressure and visual field deterioration. The AGIS Investigators. Am J Ophthalmol. 2000;130:429-40.

31. Brubaker RF. Flow of aqueous humor in humans [The Friedenwald Lecture]. Invest Ophthalmol Vis Sci. 1991;32:3145-66.

32. Drance SM. The significance of the diurnal tension variations in normal and glaucomatous eyes. Arch Ophthalmol. 1960;64:494-501.

33. David R, Zangwill L, Briscoe D, Dagan M, Yagev R, Yassur Y. Diurnal intraocular pressure variations: an analysis of 690 diurnal curves. Br J Ophthalmol. 1992;76:280-3.

34. Wilensky JT, Gieser DK, Dietsche ML, Mori MT, Zeimer R. Individual variability in the diurnal intraocular pressure curve. Ophthalmology. 1993;100:940-4.

35. Newell FW, Krill AE. Diurnal tonography in normal and glaucomatous eyes. Trans Am Ophthalmol Soc. 1964;62:349-74.
36. Katavisto M. The diurnal variations of ocular tension in glaucoma. Acta Ophthalmol. 1964:Suppl 78:1-130.

37. Chiquet C, Custaud MA, Le Traon AP, Millet C, Gharib C, Denis P. Changes in intraocular pressure during prolonged (7-day) head-down tilt bedrest. J Glaucoma. 2003;12:204-8.

38. Liu JH, Kripke DF, Hoffman RE, et al. Nocturnal elevation of intraocular pressure in young adults. Invest Ophthalmol Vis Sci. 1998;39:2707-12.

39. Liu JH, Kripke DF, Twa MD, et al. Twenty-four-hour pattern of intraocular pressure in the aging population. Invest Ophthalmol Vis Sci. 1999;40:2912-7.

40. Hara $T$, Tsuru $T$. Increase of peak intraocular pressure during sleep in reproduced diurnal changes by posture. Arch Ophthalmol. 2006;124:165-8.

41. Sacca SC, Rolando M, Marletta A, Macri A, Cerqueti P, Ciurlo G. Fluctuations of intraocular pressure during the day in open-angle glaucoma, normal-tension glaucoma and normal subjects. Ophthalmologica. 1998;212:115-9.

42. Shuba LM, Doan AP, Maley MK, et al. Diurnal fluctuation and concordance of intraocular pressure in glaucoma suspects and normal tension glaucoma patients. J Glaucoma. 2007;16:307-12.

43. Sihota R, Saxena R, Gogoi M, Sood A, Gulati V, Pandey RM. A comparison of the circadian rhythm of intraocular pressure in primary chronic angle closure glaucoma, primary open angle glaucoma and normal eyes. Indian J Ophthalmol. 2005;53:243-7.

44. Collaer N, Zeyen T, Caprioli J. Sequential office pressure measurements in the management of glaucoma. J Glaucoma. 2005;14:196-200.

45. Dinn RB, Zimmerman MB, Shuba LM, et al. Concordance of diurnal intraocular pressure between fellow eyes in primary open-angle glaucoma. Ophthalmology. 2007;114:915-20.

46. Nakakura S, Nomura Y, Ataka S, Shiraki K. Relation between office intraocular pressure and 24-hour intraocular pressure in patients with primary open-angle glaucoma treated with a combination of topical antiglaucoma eye drops. J Glaucoma. 2007;16:201-4.

47. Tanaka S, Watanabe M, Inatomi S, et al. Effects of several anti-glaucoma medications on the circadian intraocular pressure fluctuations in 
patients with primary open-angle glaucoma. J Ocul Pharmacol Ther. 2014;30:12-20.

48. Quaranta L, Konstas AGP, Rossetti L, et al. Untreated 24-h intraocular pressures measured with Goldmann applanation tonometry vs nighttime supine pressures with Perkins applanation tonometry. Eye (Lond). 2010;24:1252-8.

49. Mosaed S, Liu JH, Weinreb RN. Correlation between office and peak nocturnal intraocular pressures in healthy subjects and glaucoma patients. Am J Ophthalmol. 2005;139:320-4.

50. Lee PW, Doyle A, Stewart JA, Kristoffersen CJ, Stewart WC. Meta-analysis of timolol on diurnal and nighttime intraocular pressure and blood pressure. Eur J Ophthalmol. 2010;20:1035-41.

51. Quaranta L, Katsanos A, Floriani I, Riva I, Russo A, Konstas AG. Circadian intraocular pressure and blood pressure reduction with timolol $0.5 \%$ solution and timogel $0.1 \%$ in patients with primary open-angle glaucoma. J Clin Pharmacol. 2012;52:1552-7.

52. Feldman RM, Stewart RH, Stewart WC, Jia G, Smugar SS, Galet VA. 24-hour control of intraocular pressure with $2 \%$ dorzolamide/ $0.5 \%$ timolol fixed-combination ophthalmic solution in open-angle glaucoma. Curr Med Res Opin. 2008;24:2403-12.

53. Spaeth GL, Bernstein P, Caprioli J, Schiffman RM. Control of intraocular pressure and fluctuation with fixed-combination brimonidine-timolol versus brimonidine or timolol monotherapy. Am J Ophthalmol. 2011;151:93-9.

54. Konstas AG, Katsimpris IE, Kaltsos $\mathrm{K}$, et al. Twenty-four-hour efficacy of the brimonidine/timolol fixed combination versus therapy with the unfixed components. Eye (Lond). 2008;22:1391-7.

55. van der Valk R, Webers CA, Schouten JS, Zeegers MP, Hendrikse F, Prins MH. Intraocular pressure-lowering effects of all commonly used glaucoma drugs: a meta-analysis of randomized clinical trials. Ophthalmology. 2005;112:1177-85.

56. Liu JH, Kripke DF, Weinreb RN. Comparison of the nocturnal effects of once-daily timolol and latanoprost on intraocular pressure. Am J Ophthalmol. 2004;138:389-95.

57. Konstas AG, Quaranta L, Katsanos A, et al. Twenty-four hour efficacy with preservative free tafluprost compared with latanoprost in patients with primary open angle glaucoma or ocular hypertension. Br J Ophthalmol. 2013;97:1510-5.
58. Konstas AG, Lake S, Economou AI, Kaltsos K, Jenkins JN, Stewart WC. 24-hour control with a latanoprost-timolol fixed combination vs timolol alone. Arch Ophthalmol. 2006;124:1553-7.

59. Varma R, Hwang LJ, Grunden JW, Bean GW. Using diurnal intraocular pressure fluctuation to assess the efficacy of fixed-combination latanoprost/timolol versus latanoprost or timolol monotherapy. Br J Ophthalmol. 2010;94:80-4.

60. Quaranta L, Miglior S, Floriani I, Pizzolants T, Konstas AG. Effects of the timolol-dorzolamide fixed combination and latanoprost on circadian diastolic ocular perfusion pressure in glaucoma. Invest Ophthalmol Vis Sci. 2008;49:4226-31.

61. Konstas AG, Kozobolis VP, Tsironi S, Makridaki I, Efremova R, Stewart WC. Comparison of the 24-hour intraocular pressure-lowering effects of latanoprost and dorzolamide/timolol fixed combination after 2 and 6 months of treatment. Ophthalmology. 2008;115:99-103.

62. Tamer C, Oksuz H. Circadian intraocular pressure control with dorzolamide versus timolol maleate add-on treatments in primary open-angle glaucoma patients using latanoprost. Ophthalmic Res. 2007;39:24-31.

63. Nakamura Y, Ishikawa S, Nakamura Y, Sakai H, Henzan I, Sawaguchi S. 24-hour intraocular pressure in glaucoma patients randomized to receive dorzolamide or brinzolamide in combination with latanoprost. Clin Ophthalmol. 2009;3:395-400.

64. Lupinacci AP, Netland PA, Fung KH, Evans D, Zhao Y. Comparison of twice-daily and three-times-daily dosing of dorzolamide in ocular hypertension and primary open-angle glaucoma patients treated with latanoprost. Adv Ther. 2008;25:231-9.

65. Konstas AG, Karabatsas CH, Lallos N, et al. 24-hour intraocular pressures with brimonidine purite versus dorzolamide added to latanoprost in primary open-angle glaucoma subjects. Ophthalmology. 2005;112:603-8.

66. Katsanos A, Dastiridou AI, Fanariotis M, Kotoula M, Tsironi EE. Bimatoprost and bimatoprost/timolol fixed combination in patients with open-angle glaucoma and ocular hypertension. J Ocul Pharmacol Ther. 2011;27:67-71.

67. Rossetti L, Karabatsas $\mathrm{CH}$, Topouzis F, et al. Comparison of the effects of bimatoprost and a fixed combination of latanoprost and timolol on circadian intraocular pressure. Ophthalmology. 2007; 114:2244-51. 
68. Seibold LK, Kahook MY. The diurnal and nocturnal effect of travoprost with SofZia on intraocular pressure and ocular perfusion pressure. Am J Ophthalmol. 2014;157:44-9.

69. Konstas AG, Holló G, Haidich AB, et al. Comparison of 24-hour intraocular pressure reduction obtained with brinzolamide/timolol or brimonidine/timolol fixed-combination adjunctive to travoprost therapy. J Ocul Pharmacol Ther. 2013;29:652-7.

70. Cheng JW, Cheng SW, Gao LD, Lu GC, Wei RL. Intraocular pressure-lowering effects of commonly used fixed-combination drugs with timolol: a systematic review and meta-analysis. PLoS One. 2012;7:e45079.

71. Konstas AG, Jay JL, Marshall GE, Lee WR. Prevalence, diagnostic features, and response to trabeculectomy in exfoliation glaucoma. Ophthalmology. 1993;100:619-27.

72. Gumus K, Bozkurt B, Sonmez B, Irkec M, Orhan M, Saracbasi O. Diurnal variation of intraocular pressure and its correlation with retinal nerve fiber analysis in Turkish patients with exfoliation syndrome. Graefes Arch Clin Exp Ophthalmol. 2006;244:170-6.

73. Huchzermeyer C, Horn F, Lämmer R, Mardin CY, Jünemann AG. Short-term fluctuation of intraocular pressure is higher in patients with pseudoexfoliation syndrome despite similar mean intraocular pressure: a retrospective case-control study. Graefes Arch Clin Exp Ophthalmol. 2015;253:107-14.

74. Konstas AG, Mantziris DA, Maltezos A, Cate EA, Stewart WC. Comparison of 24 hour control with Timoptic $0.5 \%$ and Timoptic-XE $0.5 \%$ in exfoliation and primary open-angle glaucoma. Acta Ophthalmol Scand. 1999;77:541-3.

75. Konstas AG, Tsironi $\mathrm{S}$, Vakalis $\mathrm{AN}$, et al. Intraocular pressure control over 24 hours using travoprost and timolol fixed combination administered in the morning or evening in primary open-angle and exfoliative glaucoma. Acta Ophthalmol. 2009;87:71-6.

76. Konstas AG, Holló G, Mikropoulos D, et al. Twenty-four-hour intraocular pressure control with bimatoprost and the bimatoprost/timolol fixed combination administered in the morning, or evening in exfoliative glaucoma. $\mathrm{Br} \mathrm{J}$ Ophthalmol. 2010;94:209-13.

77. Stewart WC, Konstas AG, Kruft B, Mathis HM, Stewart JA. Meta-analysis of 24-h intraocular pressure fluctuation studies and the efficacy of glaucoma medicines. J Ocul Pharmacol Ther. 2010;26:175-80.

78. Wilensky JT, Gieser DK, Mori MT, Langenberg PW, Zeimer RC. Self-tonometry to manage patients with glaucoma and apparently controlled intraocular pressure. Arch Ophthalmol. 1987;105:1072-5.

79. Thomas R, Parikh R, George R, Kumar RS, Muliyil J. Five-year risk of progression of ocular hypertension to primary open angle glaucoma. A population-based study. Indian J Ophthalmol. 2003;51:329-33.

80. Gonzalez I, Pablo LE, Pueyo M, et al. Assessment of diurnal tensional curve in early glaucoma damage. Int Ophthalmol. 1996-1997;20:113-5.

81. Jonas JB, Budde WM, Stroux A, Oberacher-Velten IM, Jünemann A. Diurnal intraocular pressure profiles and progression of chronic open-angle glaucoma. Eye (Lond). 2007;21:948-51.

82. Caprioli J, Coleman AL. Intraocular pressure fluctuation a risk factor for visual field progression at low intraocular pressures in the advanced glaucoma intervention study. Ophthalmology. 2008;115:1123-9 (e3).

83. Konstas AG, Quaranta L, Mikropoulos DG, et al. Peak intraocular pressure and glaucomatous progression in primary open-angle glaucoma. J Ocul Pharmacol Ther. 2012;28:26-32.

84. Barkana Y, Anis S, Liebmann J, Tello C, Ritch R. Clinical utility of intraocular pressure monitoring outside of normal office hours in patients with glaucoma. Arch Ophthalmol. 2006;124:793-7.

85. Quaranta L, Gandolfo F, Turano R, et al. Effects of topical hypotensive drugs on circadian IOP, blood pressure, and calculated diastolic ocular perfusion pressure in patients with glaucoma. Invest Ophthalmol Vis Sci. 2006;47:2917-23.

86. Winkler NS, Fautsch MP. Effects of prostaglandin analogues on aqueous humor outflow pathways. J Ocul Pharmacol Ther. 2014;30:102-9.

87. Russo A, Riva I, Pizzolante T, Noto F, Quaranta L. Latanoprost ophthalmic solution in the treatment of open angle glaucoma or raised intraocular pressure: a review. Clin Ophthalmol. 2008;2:897-905.

88. Camras CB, the United States Latanoprost Study Group. Comparison of latanoprost and timolol in patients with ocular hypertension and glaucoma: a six-month, masked, multicenter trial in the United States. Ophthalmology. 1996;103:138-47. 
89. Alm A, Stjernschantz J. Effects on intraocular pressure and side effects of $0.005 \%$ latanoprost applied once daily, evening or morning. A comparison with timolol. Scandinavian Latanoprost Study Group. Ophthalmology. 1995;102:1743-52.

90. Konstas AG, Mikropoulos D, Kaltsos K, Jenkins JN, Stewart WC. 24-hour intraocular pressure control obtained with evening- versus morning-dosed travoprost in primary open-angle glaucoma. Ophthalmology. 2006;113:446-50.

91. Parrish RK, Palmberg P, Sheu WP. A comparison of latanoprost, bimatoprost, and travoprost in patients with elevated intraocular pressure: a 12-week, randomized, masked-evaluator multicenter study. Am J Ophthalmol. 2003;135:688-703.

92. Orzalesi N, Rossetti L, Bottoli A, Fogagnolo P. Comparison of the effects of latanoprost, travoprost, and bimatoprost on circadian intraocular pressure in patients with glaucoma or ocular hypertension. Ophthalmology. 2006;113:239-46.

93. Yildirim N, Sahin A, Gultekin S. The effect of latanoprost, bimatoprost, and travoprost on circadian variation of intraocular pressure in patients with open-angle glaucoma. J Glaucoma. 2008;17:36-9.

94. Gandolfi S, Simmons ST, Sturm R, Chen K, VanDenburgh AM, Bimatoprost Study Group 3. Three-month comparison of bimatoprost and latanoprost in patients with glaucoma and ocular hypertension. Adv Ther. 2001;18:110-21.

95. DuBiner H, Cooke D, Dirks M, Stewart WC, VanDenburgh AM, Felix C. Efficacy and safety of bimatoprost in patients with elevated intraocular pressure: a 30-day comparison with latanoprost. Surv Ophthalmol. 2001;45(Suppl 4):S353-60.

96. Aptel F, Cucherat M, Denis P. Efficacy and tolerability of prostaglandin analogs: a meta-analysis of randomized controlled clinical trials. J Glaucoma. 2008;17:667-73.

97. Aptel F, Denis P. Balancing efficacy and tolerability of prostaglandin analogues and prostaglandin-timolol fixed combinations in primary open-angle glaucoma. Curr Med Res Opin. 2011;27:1949-58.

98. Przydryga JT, Egloff C, Swiss Start Study Group. Intraocular pressure lowering efficacy of travoprost. Eur J Ophthalmol. 2004;14:416-22.

99. van der Valk R, Webers CA, Lumley T, Hendrikse F, Prins $\mathrm{MH}$, Schouten JS. A network meta-analysis combined direct and indirect comparisons between glaucoma drugs to rank effectiveness in lowering intraocular pressure. J Clin Epidemiol. 2009;62:1279-83.

100. Leske MC, Heijl A, Hyman L, et al. Predictors of long-term progression in the early manifest glaucoma trial. Ophthalmology. 2007;114:1965-72.

101. Chauhan BC, Mikelberg FS, Balaszi AG. Canadian Glaucoma Study: 2. Risk factors for the progression of open-angle glaucoma. Arch Ophthalmol. 2008;126:1030-6.

102. Tung JD, Tafreshi A, Weinreb RN, Slight JR, Medeiros FA, Liu JH. Twenty-four-hour effects of bimatoprost $0.01 \%$ monotherapy on intraocular pressure and ocular perfusion pressure. BMJ Open. 2012. doi:10.1136/bmjopen-2012-001106.

103. Ishibashi S, Hirose N, Tawara A, Kubota T. Effect of latanoprost on the diurnal variations in the intraocular and ocular perfusion pressure in normal tension glaucoma. J Glaucoma. 2006;15:354-7.

104. Quaranta L, Pizzolante T, Riva I, Haidich AB, Konstas AG, Stewart WC. Twenty-four-hour intraocular pressure and blood pressure levels with bimatoprost versus latanoprost in patients with normal-tension glaucoma. Br J Ophthalmol. 2008;92:1227-31.

105. Costagliola C, Parmeggiani F, Virgili G, et al. Circadian changes of intraocular pressure and ocular perfusion pressure after timolol or latanoprost in Caucasians with normal-tension glaucoma. Graefes Arch Clin Exp Ophthalmol. 2008;246:389-96.

106. Alm A, Widengard I. Latanoprost: experience of 2-year treatment in Scandinavia. Acta Ophthalmol Scand. 2000;78:71-6.

107. Costagliola C, Del Prete A, Verolino $M$, et al. Effect of $0.005 \%$ latanoprost once daily on intraocular pressure in glaucomatous patients not adequately controlled by beta-blockers twice daily: a 3-year follow-up. Experience and incidence of side effects in a prospective study on 76 patients. Graefes Arch Clin Exp Ophthalmol. 2002;240:379-86.

108. Watson PG. Latanoprost. Two years' experience of its use in the United Kingdom. Latanoprost Study Group. Ophthalmology. 1998;105:82-7.

109. Kashiwagi K, Tsumura T, Tsukahara S. Long-term effects of latanoprost monotherapy on intraocular pressure in Japanese glaucoma patients. J Glaucoma. 2008;17:662-6. 
110. Fristrom B, Uusitalo H. A randomized, 36-month, post-marketing efficacy and tolerability study in Sweden and Finland of latanoprost versus non-prostaglandin therapy in patients with glaucoma or ocular hypertension. Acta Ophthalmol. 2010;88:37-43.

111. Hedman K, Watson PG, Alm A. The effect of latanoprost on intraocular pressure during 2 years of treatment. Surv Ophthalmol. 2002;47(Suppl 1):S65-76.

112. Shedden A, Laurence J, Tipping R. Efficacy and tolerability of timolol maleate ophthalmic gel-forming solution versus timolol ophthalmic solution in adults with open-angle glaucoma or ocular hypertension: a six-month, double-masked, multicenter study. Clin Ther. 2001;23:440-50.

113. Topper JE, Brubaker RF. Effects of timolol, epinephrine, and acetazolamide on aqueous flow during sleep. Invest Ophthalmol Vis Sci. 1985;26:1315-9.

114. Reiss GR, Lee DA, Topper JE, Brubaker RF. Aqueous humor flow during sleep. Invest Ophthalmol Vis Sci. 1984;25:776-8.

115. Sall K. The efficacy and safety of brinzolamide $1 \%$ ophthalmic suspension (Azopt) as a primary therapy in patients with open-angle glaucoma or ocular hypertension. Brinzolamide Primary Therapy Study Group. Surv Ophthalmol. 2000;44(Suppl 2):S155-62.

116. Wilkerson M, Cyrlin M, Lippa EA, et al. Four-week safety and efficacy study of dorzolamide, a novel, active topical carbonic anhydrase inhibitor. Arch Ophthalmol. 1993;111:1343-50.

117. Strahlman E, Tipping R, Vogel R. A double-masked, randomized 1-year study comparing dorzolamide (Trusopt), timolol, and betaxolol. International Dorzolamide Study Group. Arch Ophthalmol. 1995;113:1009-16.

118. Toris CB, Zhan GL, Yablonski ME, Camras CB. Effects on aqueous flow of dorzolamide combined with either timolol or acetazolamide. J Glaucoma. 2004;13:210-5.

119. Vanlandingham BD, Maus TL, Brubaker RF. The effect of dorzolamide on aqueous humor dynamics in normal human subjects during sleep. Ophthalmology. 1998;105:1537-40.

120. Maus TL, McLaren JW, Shepard JW, Brubaker RF. The effects of sleep on circulating catecholamines and aqueous flow in human subjects. Exp Eye Res. 1996;62:351-8.
121. Stewart WC, Sharpe ED, Harbin TS Jr, et al. Brimonidine $0.2 \%$ versus dorzolamide $2 \%$ each given three times daily to reduce intraocular pressure. Am J Ophthalmol. 2000;129:723-7.

122. Serle JB. A comparison of the safety and efficacy of twice daily brimonidine $0.2 \%$ versus betaxolol $0.25 \%$ in subjects with elevated intraocular pressure. The Brimonidine Study Group III. Surv Ophthalmol. 1996;41(Suppl 1):S39-47.

123. Liu JH, Medeiros FA, Slight JR, Weinreb RN. Diurnal and nocturnal effects of brimonidine monotherapy on intraocular pressure. Ophthalmology. 2010;117:2075-9.

124. Whitson JT, Henry C, Hughes B, Lee DA, Terry S, Fechtner RD. Comparison of the safety and efficacy of dorzolamide $2 \%$ and brimonidine $0.2 \%$ in patients with glaucoma or ocular hypertension. J Glaucoma. 2004;13:168-73.

125. Lichter PR, Musch DC, Gillespie BW, et al. Interim clinical outcomes in the Collaborative Initial Glaucoma Treatment Study comparing initial treatment randomized to medications or surgery. Ophthalmology. 2001;108:1943-53.

126. Dunker S, Schmucker A, Maier H. Tolerability, quality of life, and persistency of use in patients with glaucoma who are switched to the fixed combination of latanoprost and timolol. Adv Ther. 2007;24:376-86.

127. Quaranta L, Biagioli E, Riva I, et al. Prostaglandin analogs and timolol-fixed versus unfixed combinations or monotherapy for open-angle glaucoma: a systematic review and meta-analysis. J Ocul Pharmacol Ther. 2013;29:382-9.

128. Webers CA, Beckers HJ, Zeegers MP, Nuijts RM, Hendrikse F, Schouten JS. The intraocular pressure-lowering effect of prostaglandin analogs combined with topical $\beta$-blocker therapy: a systematic review and meta-analysis. Ophthalmology. 2010;117:2067-74.

129. Konstas AG, Pikilidou MI, Tsironi S, et al. 24-hour intraocular pressure and blood pressure levels with latanoprost/timolol fixed combination versus timolol. Curr Eye Res. 2009;34:369-77.

130. Konstas AG, Voudouragkaki IC, Boboridis KG, et al. 24-hour efficacy of travoprost/timolol BAK-free versus latanoprost/timolol fixed combinations in patients insufficiently controlled with latanoprost. Adv Ther. 2014;31:592-603.

131. Konstas AG, Holló G, Mikropoulos DG, et al. 24-hour efficacy of the bimatoprost-timolol fixed 
combination versus latanoprost as first choice therapy in subjects with high-pressure exfoliation syndrome and glaucoma. $\mathrm{Br} \mathrm{J}$ Ophthalmol. 2013;97:857-61.

132. Eren MH, Gungel H, Altan C, Pasaoglu IB, Sabanci S. Comparison of dorzolamide/timolol and latanoprost/timolol fixed combinations on diurnal intraocular pressure control in primary open-angle glaucoma. J Ocul Pharmacol Ther. 2012;28:381-6.

133. Konstas AG, Quaranta L, Yan DB, et al. Twenty-four hour efficacy with the dorzolamide/timolol-fixed combination compared with the brimonidine/timolol-fixed combination in primary open-angle glaucoma. Eye (Lond). 2012;26:80-7.

134. Wise JB, Witter SL. Argon laser therapy for open-angle glaucoma. A pilot study. Arch Ophthalmol. 1979;97:319-22.

135. The Glaucoma Laser Trial (GLT). 2. Results of argon laser trabeculoplasty versus topical medicines. The Glaucoma Laser Trial Research Group. Ophthalmology. 1990;97:1403-13.

136. Spaeth GL, Baez KA. Argon laser trabeculoplasty controls one third of cases of progressive, uncontrolled, open angle glaucoma for 5 years. Arch Ophthalmol. 1992;110:491-4.

137. Latina MA, Sibayan SA, Shin DH, Noecker RJ, Marcellino G. Q-switched 532-nm Nd:YAG laser trabeculoplasty (selective laser trabeculoplasty): a multicenter, pilot, clinical study. Ophthalmology. 1998;105:2082-8 (discussion 2089-90).

138. Stein JD, Challa P. Mechanisms of action and efficacy of argon laser trabeculoplasty and selective laser trabeculoplasty. Curr Opin Ophthalmol. 2007;18:140-5.

139. Damji KF, Shah KC, Rock WJ, Bains HS, Hodge WG. Selective laser trabeculoplasty $\mathrm{v}$ argon laser trabeculoplasty: a prospective randomised clinical trial. Br J Ophthalmol. 1999;83:718-22.

140. Juzych MS, Chopra V, Banitt MR, et al. Comparison of long-term outcomes of selective laser trabeculoplasty versus argon laser trabeculoplasty in open-angle glaucoma. Ophthalmology. 2004;111:1853-9.

141. Martinez-de-la-Casa JM, Garcia-Feijoo J, Castillo A, et al. Selective vs argon laser trabeculoplasty: hypotensive efficacy, anterior chamber inflammation, and postoperative pain. Eye (Lond). 2004;18:498-502.
142. Hong BK, Winer JC, Martone JF, Wand M, Altman B, Shields B. Repeat selective laser trabeculoplasty. J Glaucoma. 2009;18:180-3.

143. Russo V, Barone A, Cosma A, Stella A, Delle Noci N. Selective laser trabeculoplasty versus argon laser trabeculoplasty in patients with uncontrolled open-angle glaucoma. Eur J Ophthalmol. 2009;19:429-34.

144. Realini T. Selective laser trabeculoplasty: a review. J Glaucoma. 2008;17:497-502.

145. Nagar M, Luhishi E, Shah N. Intraocular pressure control and fluctuation: the effect of treatment with selective laser trabeculoplasty. $\mathrm{Br} J$ Ophthalmol. 2009;93:497-501.

146. Prasad N, Murthy S, Dagianis JJ, Latina MA. A comparison of the intervisit intraocular pressure fluctuation after 180 and 360 degrees of selective laser trabeculoplasty (SLT) as a primary therapy in primary open angle glaucoma and ocular hypertension. J Glaucoma. 2009;18:157-60.

147. Bagga H, Liu JH, Weinreb RN. Intraocular pressure measurements throughout the $24 \mathrm{~h}$. Curr Opin Ophthalmol. 2009;20:79-83.

148. Agarwal HC, Sihota R, Das C, Dada T. Role of argon laser trabeculoplasty as primary and secondary therapy in open angle glaucoma in Indian patients. Br J Ophthalmol. 2002;86:733-6.

149. Greenidge KC, Spaeth GL, Fiol-Silva Z. Effect of argon laser trabeculoplasty on the glaucomatous diurnal curve. Ophthalmology. 1983;90:800-4.

150. Lee AC, Mosaed S, Weinreb RN, Kripke DF, Liu JH. Effect of laser trabeculoplasty on nocturnal intraocular pressure in medically treated glaucoma patients. Ophthalmology. 2007;114:666-70.

151. Nagar M, Ogunyomade A, O'Brart DP, Howes F, Marshall J. A randomised, prospective study comparing selective laser trabeculoplasty with latanoprost for the control of intraocular pressure in ocular hypertension and open angle glaucoma. Br J Ophthalmol. 2005;89:1413-7.

152. Kóthy P, Tóth M, Holló G. Influence of selective laser trabeculoplasty on 24-hour diurnal intraocular pressure fluctuation in primary open-angle glaucoma: a pilot study. Ophthalmic Surg Lasers Imaging. 2010;41:342-7.

153. Tojo N, Oka M, Miyakoshi A, Ozaki H, Hayashi A. Comparison of fluctuations of intraocular pressure before and after selective laser trabeculoplasty in normal-tension glaucoma patients. J Glaucoma. 2014;23:e138-43. 
154. Magacho L, Toscano DA, Freire G, Shetty RK, Avila MP. Comparing the measurement of diurnal fluctuations in intraocular pressure in the same day versus over different days in glaucoma. Eur J Ophthalmol. 2010;20:542-5.

155. Stewart WC, Kolker AE, Sharpe ED, et al. Factors associated with long-term progression or stability in primary open-angle glaucoma. Am J Ophthalmol. 2000;130:274-9.

156. Konstas AG, Holló G, Astakhov YS, et al. Factors associated with long-term progression or stability in exfoliation glaucoma. Arch Ophthalmol. 2004;122:29-33.

157. Saiz A, Alcuaz A, Maquet JA, de la Fuente F. Pressure-curve variations after trabeculectomy for chronic primary open-angle glaucoma. Ophthalmic Surg. 1990;21:799-801.

158. Gandolfi SA, Vecchi M. 5-fluorouracil in combined trabeculectomy and clear-cornea phacoemulsification with posterior chamber intraocular lens implantation. A one-year randomized, controlled clinical trial. Ophthalmology. 1997;104:181-6.

159. Medeiros FA, Pinheiro A, Moura FC, Leal BC, Susanna R Jr. Intraocular pressure fluctuations in medical versus surgically treated glaucomatous patients. J Ocul Pharmacol Ther. 2002;18:489-98.

160. Mansouri K, Orguel S, Mermoud A, et al. Quality of diurnal intraocular pressure control in primary open-angle patients treated with latanoprost compared with surgically treated glaucoma patients: a prospective trial. $\mathrm{Br} \mathrm{J}$ Ophthalmol. 2008;92:332-6.

161. Matsuoka M, Ando A, Minamino K, et al. Dampening of diurnal intraocular pressure fluctuation by combined trabeculotomy and sinusotomy in eyes with open-angle glaucoma. J Glaucoma. 2013;22:290-3.

162. Klink T, Praetorius S, Leippi S, Klink J, Grehn FJ. Diurnal and nocturnal intraocular pressure fluctuations after trabeculectomy. Ophthalmologica. 2012;227:160-5.

163. Liang YB, Xie C, Meng LH, et al. Daytime fluctuation of intraocular pressure in patients with primary angle-closure glaucoma after trabeculectomy. J Glaucoma. 2013;22:349-54.

164. Gloor B, Meier-Gibbons F. Principles of effectiveness control in therapy of glaucoma. Ophthalmologe. 1996;93:510-9.

165. Mansouri K, Shaarawy T. Continuous intraocular pressure monitoring with a wireless ocular telemetry sensor: initial clinical experience in patients with open angle glaucoma. $\mathrm{Br} J$ Ophthalmol. 2011;95:627-9.

166. Holló G, Kóthy P, Vargha P. Evaluation of continuous 24-hour intraocular pressure monitoring for assessment of prostaglandin-induced pressure reduction in glaucoma. J Glaucoma. 2014;23:e6-12. 